\title{
TESTS ON SLENDER DUCTILE STRUCTURAL WALLS DESIGNED ACCORDING TO NEW ZEALAND STANDARD
}

\author{
Farhad Dashti $^{1}$, Rajesh P. Dhakal ${ }^{2}$ and Stefano Pampanin ${ }^{3}$
}

(Submitted April 2017; Reviewed May 2017; Accepted July 2017)

\begin{abstract}
This paper presents an experimental study conducted to investigate the seismic performance and out-ofplane response of three rectangular doubly reinforced ductile wall specimens subjected to an in-plane cyclic quasi-static loading. The specimens were half-scale, representing the first story of four story prototype walls designed according to NZS3101:2006. The experimental program including details of the specimens, material properties, test setup, loading protocol and instrumentation is described. Also, the test observations, with focus on the significant stages of wall response as well as the failure patterns of the specimens, are reported considering the correlation between seismic damage and lateral drift. Two of the specimens failed at $2 \%$ drift, and their failure modes comprised of bar fracture, bar buckling, concrete crushing and out-of-plane instability. The failure pattern of the third specimen was pure out-of-plane instability which proved to have the potential to cause sudden collapse of slender ductile walls that are designed to resist other failure modes. In light of the test results, the efficacy of wall design provisions in the New Zealand concrete design standard (NZS3101) associated with the observed failure modes is scrutinised.
\end{abstract}

\section{INTRODUCTION}

Structural walls (also known as shear walls) are one of the common lateral load resisting elements in reinforced concrete (RC) buildings in seismic regions. Unlike other structural elements, structural walls are considerably longer in one cross sectional dimension compared to the other to provide shear and moment resisting capacities in the desired direction. A relatively high stiffness is consequently provided by a structural wall along its in-plane direction making it the main lateral force resisting system of the structure. As a result, this structural system needs to satisfy the seismic requirements, i.e. to prevent damage to non-structural elements during minor earthquakes, limit structural damage in moderate earthquakes and prevent the collapse of the building during major seismic events. To achieve this level of reliability, a structural wall needs to respond to seismic actions with enough ductility and energy dissipation capacity. Hence, any mode of failure that is bound to interfere with its operation must be impeded until the desired performance level is achieved. As a consequence, the failure modes that different types of structural walls are likely to sustain should be identified.

The performance of modern structural walls in the Chile (February 2010) and New Zealand (February 2011) earthquakes has exposed some problems with the existing design of RC structural walls. The main issues lie around the buckling of bars, out-of-plane deformation of the wall, reinforcement getting snapped beneath a solitary thin crack, etc $[1,2]$. Therefore, the seismic performance of modern, code-compliant walls needs to be further investigated. $\mathrm{Lu}$ et al [3] conducted a series of tests on six RC walls designed in accordance with the current minimum vertical reinforcement requirements in New Zealand Concrete Structures Standard NZS 3101: 2006 Amendment 2 (A2) [4] and Shegay et al [5] conducted large-scale testing on New-Zealand code-compliant $\mathrm{RC}$ wall specimens under high axial loads.
Development of out-of-plane instability in rectangular walls was observed in several wall tests [6-8]. Birely [9] observed out-of-plane movement in one of the specimens that were designed using the ACI 318-05 Building Code and also met the requirements of the ACI 318-08 Building Code. However, the specimen was reported to have failed due to bar buckling and concrete crushing at one of the boundary regions which resulted in loss of axial capacity of the specimen.

The instability of rectangular walls has generally been investigated by testing concrete columns representing boundary zones of rectangular walls under axial cyclic loading. This type of research on out-of-plane instability failure was first conducted by Goodsir [10]. Chai and Elayer [11] also conducted an experimental study to examine the outof-plane instability of several RC columns that were designed to represent the end-regions of a ductile planar $\mathrm{RC}$ wall under large amplitude reversed cyclic tension and compression. Based on this study, the critical influence of the maximum tensile strain on the lateral instability of slender rectangular walls was confirmed and the basic behaviour of the wall endregions under an axial tension and compression cycle was described by axial strain versus out-of-plane displacement and axial strain versus axial force plots. The effect of the specimen thickness was studied in this research, as well. Creagh et al. [12] and Chrysanidis and Tegos [13] subjected concrete prisms to tension and then to compression until failure. The results of these experiments confirmed the effect of maximum tensile strain developed during the tensile loading on out-ofplane instability of the specimen during the compressive loading. In another test campaign by Shea et al. [14], the influence of specimen thickness as well as the maximum tensile strain on the out-of-plane instability failure was investigated. Almeida et al. [15] investigated the out-of-plane failure mode of walls by analysing the response of two singly reinforced T-shaped walls tested under cyclic loading. The specimens were identical but were subjected to two different in-plane and bi-directional loading patterns.

\footnotetext{
1 Corresponding Author, Research Engineer, UC Quake Centre, University of Canterbury, New Zealand. farhad.dashti@canterbury.ac.nz (Member)

2 Professor, University of Canterbury, New Zealand. rajesh.dhakal@canterbury.ac.nz (Fellow)

3 Professor, University of Canterbury, New Zealand, \& Professor, Sapienza University of Rome, Italy, stefano.pampanin@canterbury.ac.nz (Fellow)
} 
In this paper, details of an experimental campaign conduced on the parameters known to be influential on out-of-plane instability of rectangular doubly reinforced structural walls are presented and seismic performance of the specimens, which were designed according to the current New Zealand concrete standard [4], are discussed. Specifically, i) the likely failure mode of typical rectangular RC walls designed to satisfy NZS3101 requirements, ii) adequacy of NZS3101 provisions to prevent different failure modes of rectangular walls, and iii) effects of geometrical parameters (such as length and thickness) on the failure mode of rectangular RC walls are discussed. Due to space limitation, only the key aspects of the experimental results are presented herein, and interested readers are referred to the first author's $\mathrm{PhD}$ thesis [16] for further details.

\section{TEST MATRIX}

In order to identify the parameters affecting the initiation and development of out-of-plane deformation in rectangular walls, a parametric study was conducted using a numerical model that had been verified for its capability to simulate different failure modes of rectangular walls [17]. In addition to the parametric study, a detailed investigation of the wall response at the material level and at different stages of development of the out-of-plane deformation was carried out and the formation of out-of-plane deformation in the numerical model was scrutinized with reference to the postulations and experimental observations of other researchers. Wall thickness, wall length and axial load ratio were identified as the main parameters controlling this mode of deformation in rectangular walls. A four-specimen test matrix was hence designed (Table 1) to investigate the effect of these parameters. However, due to the structural laboratory decanting and refurbishment process, the test of the 4th specimen had to be postponed until 2018. All four specimens were designed according to the latest version of the New Zealand Concrete Standard [4].

Table 1. Test specimens.

\begin{tabular}{ll}
\hline Parameter & Specimen \\
\hline & RWB (Benchmark specimen) \\
\hline Wall thickness, $\mathrm{t}_{\mathrm{w}}$ & RWT (Thickness increased) \\
\hline Wall length, $\mathrm{l}_{\mathrm{w}}$ & RWL (Length decreased) \\
\hline Axial load & RWA (Axial load increased) \\
\hline
\end{tabular}

Specimen RWB was considered the benchmark specimen. All other specimens differed from the benchmark specimen in just one of the above-mentioned three parameters while satisfying roughly identical moment capacities as the benchmark specimen. As the specimens were considered to be different alternatives for a specific loading condition, the value of axial load was kept constant for Specimens RWB, RWT, and RWL; i.e. the axial load ratio had to vary due to the variations of the cross-section geometry in addition to the unavoidable differences in concrete strength. Specimen RWT differed from Specimen RWB in its thickness ( $8 \%$ increase). Specimen RWL was shorter than Specimen RWB (20\% decrease), and consequently had larger longitudinal reinforcement ratio in the boundary region to compensate for the reduction of the moment capacity coming from the reduction of the flexural lever arm of the section. Specimen RWA was identical in geometry and reinforcement characteristics to Specimen RWB and was supposed to be subjected to a higher axial load ratio. The test specimens were half-scale models, representing the first story of a multi-storey high wall and had a shear span of $6.0 \mathrm{~m}$. The unsupported height of the specimens was $2.0 \mathrm{~m}$; thereby representing a storey height of $4.0 \mathrm{~m}$. To safeguard against premature out-of-plane buckling in the potential plastic hinge region of the walls, the dimension limitations of Section 11.4.2 of the New Zealand Concrete Standard [4] were checked. For walls with axial force levels greater than $0.05 \mathrm{f}_{\mathrm{c}} \mathrm{A}_{\mathrm{g}}$ and for ductile or limited ductile plastic regions a minimum thickness shall be provided in the boundary region of the wall section, extending over the lesser of the plastic hinge length or the full height of the first storey. This minimum thickness was satisfied for all specimens.

In order to comply with the capacity design approach, the specimens were designed such that after considerations of the over-strength factors, their response would be flexuraldominated. The shear demand corresponding to the flexural capacity of the designed sections with considerations of all possible over-strength factors was used for shear design of the walls as well as the test setup design. The specimens were designed assuming a concrete compressive strength of $35 \mathrm{MPa}$ and reinforcing steel with yield strength of $300 \mathrm{MPa}$. The longitudinal reinforcement was designed to meet the design shear demands (i.e., for a moment resulting from the shear demand and the effective height of the wall). The reinforcement layout was established using an iterative approach to achieve the nominal moment strength while all code requirements (i.e., confinement requirements, etc.) are met. The transverse reinforcement provided at the boundary regions complied with the lateral restraint provisions of Clause 11.4.6.3 of NZS3101. Figure 1 displays the geometry and reinforcement configurations of the specimens. Material properties of the specimens are provided in Table 2 and Table 3 , and Table 4 lists the general characteristics of the specimens. A summary of the specimen design according to the wall design provisions given in NZS3101:2006 is presented in Table 5. The detailing requirements are defined based on the classification of ductile plastic region (DPR) of NZS3101:2006.

Table 2. Compressive strength of concrete.

\begin{tabular}{cc}
\hline Specimen & $f_{c}^{\prime}(M P a)$ \\
\hline RWB & 41.3 \\
\hline RWT & 34.5 \\
\hline RWL & 34.8 \\
\hline RWA* & 38.0 \\
\hline
\end{tabular}

Table 3. Properties of reinforcing steel.

\begin{tabular}{ccccc}
\hline Bar & R6 & D10 & D12 & D16 \\
\hline$E(\mathrm{MPa})$ & 166000 & 228560 & 170235 & 168210 \\
\hline$f_{y}(\mathrm{MPa})$ & 411 & 330 & 334 & 366 \\
\hline$f_{s h}(\mathrm{MPa})$ & - & 332 & 340 & 369 \\
\hline$f_{u}(\mathrm{MPa})$ & 506 & 460 & 509 & 478 \\
\hline$\varepsilon_{y}$ & 0.0025 & 0.0014 & 0.0021 & 0.0023 \\
\hline$\varepsilon_{s h}$ & - & 0.011 & 0.019 & 0.0157 \\
\hline$\varepsilon_{u}$ & 0.08 & 0.2 & 0.19 & 0.185 \\
\hline \multicolumn{4}{l}{ D refers to deformed bars, R to plain round bars $)$}
\end{tabular}


Table 4. General characteristics of the specimens.

\begin{tabular}{|c|c|c|c|c|c|c|c|c|c|}
\hline \multirow{2}{*}{ Parameter } & \multirow{2}{*}{ Specimen } & \multirow{2}{*}{$\begin{array}{l}\text { Length, } \\
1_{\mathrm{w}}, \mathrm{mm}\end{array}$} & \multirow{2}{*}{$\begin{array}{l}\text { Thickness, } \\
\mathrm{t}_{\mathrm{w}}, \mathrm{mm}\end{array}$} & \multirow{2}{*}{$\begin{array}{l}\text { Shear- } \\
\text { span } \\
\text { ratio }\end{array}$} & \multirow{2}{*}{$\begin{array}{c}\text { Length of } \\
\text { boundary } \\
\text { elements, } 1_{C}, \mathrm{~mm}\end{array}$} & \multirow{2}{*}{$\begin{array}{l}\text { Axial } \\
\text { load, } \\
\mathrm{kN}\end{array}$} & \multirow{2}{*}{$\begin{array}{l}\text { Axial load } \\
\text { ratio, } \\
\mathrm{N} / \mathrm{f}_{\mathrm{c}} \mathrm{A}_{\mathrm{g}}\end{array}$} & \multicolumn{2}{|c|}{$\begin{array}{c}\text { Longitudinal reinforcement } \\
\text { ratio, } \rho=A_{S} / A_{C}\end{array}$} \\
\hline & & & & & & & & $\begin{array}{l}\text { Boundary } \\
\text { region }\end{array}$ & Web \\
\hline Benchmark & RWB & 2000 & 125 & 3.0 & 350 & 438 & 0.042 & 0.026 & 0.0059 \\
\hline Thickness & RWT & 2000 & 135 & 3.0 & 350 & 438 & 0.047 & 0.024 & 0.0055 \\
\hline Length & RWL & 1600 & 125 & 3.75 & 300 & 438 & 0.063 & 0.043 & 0.012 \\
\hline Axial load & RWA & 2000 & 125 & 3.0 & 350 & 657 & $0.07 *$ & 0.026 & 0.0059 \\
\hline
\end{tabular}

Table 5. Summary of the specimen design according to NZS3101:2006 wall design provisions.

\begin{tabular}{|c|c|c|c|c|c|c|c|}
\hline \multirow{2}{*}{ Requirement } & \multirow{2}{*}{ NZS 3101:2006 } & \multicolumn{6}{|c|}{ Provided/Required Ratio } \\
\hline & & \multicolumn{2}{|c|}{ RWB } & \multicolumn{2}{|c|}{ RWT } & \multicolumn{2}{|c|}{ RWL } \\
\hline Minimum thickness-general & $100 \mathrm{~mm}$ & \multicolumn{2}{|c|}{$\begin{array}{l}2.5 * 1 \text { (Prototype) } \\
\text { Req.: } 100 \mathrm{~mm} \\
\text { Prov.: } 250 \mathrm{~mm}\end{array}$} & \multicolumn{2}{|c|}{$\begin{array}{l}2.7^{* 1} \text { (Prototype) } \\
\text { Req.: } 100 \mathrm{~mm} \\
\text { Prov.: } 270 \mathrm{~mm}\end{array}$} & \multicolumn{2}{|c|}{$\begin{array}{l}2.5^{* 1} \text { (Prototype) } \\
\text { Req.: } 100 \mathrm{~mm} \\
\text { Prov.: } 250 \mathrm{~mm}\end{array}$} \\
\hline $\begin{array}{l}\text { Minimum thickness for prevention of } \\
\text { instability within plastic hinge region }\end{array}$ & $\begin{array}{c}\mathrm{b}_{\mathrm{m}}=\frac{\alpha_{\mathrm{r}} \mathrm{k}_{\mathrm{m}} \beta\left(\mathrm{A}_{\mathrm{r}}+2\right) \mathrm{L}_{\mathrm{w}}}{1700 \sqrt{\xi}} \\
\beta=7(D P R) \\
\beta=5(L D P R)\end{array}$ & \multicolumn{2}{|c|}{$\begin{array}{c}1.17 *^{2} \text { (Specimen) } \\
\text { Req.: } 107 \mathrm{~mm} \\
\text { Prov.: } 125 \mathrm{~mm}\end{array}$} & \multicolumn{2}{|c|}{$\begin{array}{c}1.27 * 2 \text { (Specimen) } \\
\text { Req.: } 107 \mathrm{~mm} \\
\text { Prov.: } 135 \mathrm{~mm}\end{array}$} & \multicolumn{2}{|c|}{$\begin{array}{c}1.25^{* 2}(\text { Specimen }) \\
\text { Req.: } 100 \mathrm{~mm} \\
\text { Prov.: } 125 \mathrm{~mm}\end{array}$} \\
\hline \multirow[b]{2}{*}{ Minimum longitudinal reinforcement ratio } & \multirow[b]{2}{*}{$\rho_{n}=\frac{\sqrt{\mathrm{f}_{\mathrm{c}}^{\prime}}}{4 \mathrm{f}_{\mathrm{y}}}$} & Boundary & Panel & Boundary & Panel & Boundary & Panel \\
\hline & & $\begin{array}{c}\quad 4.8 \\
\text { Req.:0.005 } \\
\text { Prov.: } 0.024\end{array}$ & $\begin{array}{c}1.2 \\
\text { Req.:0.005 } \\
\text { Prov.:0.006 }\end{array}$ & $\begin{array}{c}4.4 \\
\text { Req.:0.005 } \\
\text { Prov.:0.022 }\end{array}$ & $\begin{array}{c}1.1 \\
\text { Req.:0.005 } \\
\text { Prov.:0.0055 }\end{array}$ & \begin{tabular}{|c|}
8.0 \\
Req.:0.005 \\
Prov.:0.04
\end{tabular} & $\begin{array}{c}1.7 \\
\text { Req.:0.005 } \\
\text { Prov.:0.0084 }\end{array}$ \\
\hline \multirow[b]{2}{*}{$\begin{array}{l}\text { Maximum longitudinal reinforcement ratio } \\
\qquad\left(\rho_{l}\right)\end{array}$} & \multirow[b]{2}{*}{$\frac{16}{f_{y}}$} & Boundary & Panel & Boundary & Panel & Boundary & Panel \\
\hline & & $\begin{array}{c}2.2 \\
\text { Max.: } 0.053 \\
\text { Prov.: } 0.024\end{array}$ & $\begin{array}{c}\quad 8.8 \\
\text { Max.:0.053 } \\
\text { Prov.:0.006 }\end{array}$ & $\begin{array}{c}2.4 \\
\text { Max.: } 0.053 \\
\text { Prov.: } 0.022\end{array}$ & \begin{tabular}{|c|}
9.6 \\
Max.:0.053 \\
Prov.:0.0055
\end{tabular} & $\begin{array}{c}1.3 \\
\text { Max.:0.053 } \\
\text { Prov.:0.04) }\end{array}$ & $\begin{array}{c}6.3 \\
\text { Max.:0.053 } \\
\text { Prov.:0.0084 }\end{array}$ \\
\hline \multirow[b]{2}{*}{$\begin{array}{l}\text { Maximum spacing of longitudinal } \\
\text { reinforcement }(\mathbf{m m})\end{array}$} & \multirow[b]{2}{*}{$\min \left\{\mathrm{L}_{\mathrm{w}} / 3,3 \mathrm{t}\right.$, or $\left.450 \mathrm{~mm}\right\}$} & Boundary & Panel & Boundary & Panel & Boundary & Panel \\
\hline & & $\begin{array}{c}5.0 \\
\text { Max.:375 } \\
\text { Prov.:75 }\end{array}$ & $\begin{array}{c}1.8 \\
\text { Max.:375 } \\
\text { Prov.: } 210\end{array}$ & $\begin{array}{c}5.4 \\
\text { Max.: } 405 \\
\text { Prov.: } 75\end{array}$ & $\begin{array}{c}1.9 \\
\text { Max.:405 } \\
\text { Prov.: } 210\end{array}$ & \begin{tabular}{|c|}
4.7 \\
Max.:375 \\
Prov.: 80 \\
\end{tabular} & $\begin{array}{c}2.5 \\
\text { Max.:375 } \\
\text { Prov.: } 150\end{array}$ \\
\hline \multirow[t]{2}{*}{$\begin{array}{l}\text { Anti-buckling reinforcement (Within the } \\
\text { potential plastic hinge region) }\end{array}$} & $\begin{array}{c}\text { Where } \rho_{\mathrm{l}}>\left\{\begin{array}{l}\frac{2}{\mathrm{f}_{\mathrm{y}}} \text { DPR } \\
\frac{3}{\mathrm{f}_{\mathrm{y}}} \text { LDPR }\end{array}\right\} \\
\mathrm{A}_{\mathrm{te}}=\frac{\sum \mathrm{A}_{\mathrm{b}} \mathrm{f}_{\mathrm{y}}}{96 \mathrm{f}_{\mathrm{yt}}} \frac{\mathrm{s}}{\mathrm{d}_{\mathrm{b}}}\end{array}$ & \multicolumn{2}{|c|}{$\begin{array}{l}\quad 2.5 \\
\text { Req.: } 11 \mathrm{~mm}^{2} \\
\text { Prov.: } 28 \mathrm{~mm}^{2}\end{array}$} & \multicolumn{2}{|c|}{$\begin{array}{l}\quad 2.5 \\
\text { Req.: } 11 \mathrm{~mm}^{2} \\
\text { Prov.: } 28 \mathrm{~mm}^{2}\end{array}$} & \multicolumn{2}{|c|}{$\begin{array}{l}\quad 1.75 \\
\text { Req.: } 16 \mathrm{~mm}^{2} \\
\text { Prov.: } 28 \mathrm{~mm}^{2}\end{array}$} \\
\hline & Spacing $\leq\left\{\begin{array}{c}6 \mathrm{~d}_{\mathrm{b}}(\mathrm{DPR}) \\
10 \mathrm{~d}_{\mathrm{b}}(\mathrm{LDPR})\end{array}\right\}$ & \multicolumn{2}{|c|}{$\begin{array}{c}1.31 \\
\text { Max.: } 72 \mathrm{~mm} \\
\text { Prov.: } 55 \mathrm{~mm}\end{array}$} & \multicolumn{2}{|c|}{$\begin{array}{c}1.31 \\
\text { Max.: } 72 \mathrm{~mm} \\
\text { Prov.: } 55 \mathrm{~mm}\end{array}$} & \multicolumn{2}{|c|}{$\begin{array}{c}1.6 \\
\text { Max.: } 96 \mathrm{~mm} \\
\text { Prov.: } 60 \mathrm{~mm}\end{array}$} \\
\hline Confinement reinforcement & $\begin{array}{l}\text { Where neutral axis depth }>c_{c}= \\
\frac{0.1 \phi_{\mathrm{ow}_{\mathrm{w}}} \mathrm{L}_{\mathrm{w}}}{\lambda} \\
\lambda=2.0(\mathrm{DPR}) \\
\lambda=1.0(\mathrm{LDPR}) \\
\mathrm{A}_{\mathrm{sh}}=\alpha \mathrm{s}_{\mathrm{h}} \mathrm{h}^{\prime \prime} \frac{\mathrm{A}_{\mathrm{g}}^{*}}{\mathrm{~A}_{\mathrm{c}}^{*}} \frac{\mathrm{f}_{\mathrm{c}}^{\prime}}{\mathrm{f}_{\mathrm{yh}}}\left(\frac{\mathrm{c}}{\mathrm{L}_{\mathrm{w}}}-0.07\right) \\
\alpha=0.25(\mathrm{DPR}) \\
\alpha=0.175(\mathrm{LDPR})\end{array}$ & \multicolumn{2}{|c|}{$\begin{array}{c}1.29 \\
\text { Req.: } 87 \mathrm{~mm}^{2} \\
\text { Prov.: } 112 \mathrm{~mm}^{2}\end{array}$} & \multicolumn{2}{|c|}{$\begin{array}{c}1.33 \\
\text { Req.: } 84 \mathrm{~mm}^{2} \\
\text { Prov.: } 112 \mathrm{~mm}^{2}\end{array}$} & \multicolumn{2}{|c|}{$\begin{array}{c}1.23 \\
\text { Req.: } 91 \mathrm{~mm}^{2} \\
\text { Prov.: } 112 \mathrm{~mm}^{2}\end{array}$} \\
\hline $\begin{array}{l}\text { Maximum spacing of confinement } \\
\text { reinforcement }\end{array}$ & $\begin{array}{l}\text { DPR: } \min \left\{6 \mathrm{~d}_{\mathrm{b}}, 0.5 \mathrm{t}\right\} \\
\text { LDPR: } \min \left\{10 \mathrm{~d}_{b}, \mathrm{t}\right\}\end{array}$ & $\begin{array}{l}\text { Max } \\
\text { Prov }\end{array}$ & $\begin{array}{l}.15 \\
63 \mathrm{~mm} \\
55 \mathrm{~mm} \\
\end{array}$ & \multicolumn{2}{|c|}{$\begin{array}{c}1.24 \\
\text { Max.: } 68 \mathrm{~mm} \\
\text { Prov.: } 55 \mathrm{~mm}\end{array}$} & \multicolumn{2}{|c|}{$\begin{array}{c}1.05 \\
\text { Max.: } 63 \mathrm{~mm} \\
\text { Prov.: } 60 \mathrm{~mm}\end{array}$} \\
\hline Minimum confinement length & $\begin{array}{c}\max \left\{\begin{array}{c}\mathrm{c}-0.7 \mathrm{c}_{\mathrm{c}} \\
0.5 \mathrm{c}\end{array}\right\} \\
\text { c: neutral axis depth }\end{array}$ & $\begin{array}{l}\text { Min. } \\
\text { Prov. }\end{array}$ & $\begin{array}{l}.67 \\
210 \mathrm{~mm} \\
350 \mathrm{~mm}\end{array}$ & \multicolumn{2}{|c|}{$\begin{array}{c}1.67 \\
\text { Min.: } 210 \mathrm{~mm} \\
\text { Prov.: } 350 \mathrm{~mm}\end{array}$} & \multicolumn{2}{|c|}{$\begin{array}{c}1.18 \\
\text { Min.: } 255 \mathrm{~mm} \\
\text { Prov.: } 300 \mathrm{~mm}\end{array}$} \\
\hline Maximum nominal shear stress & $\mathrm{v}_{\mathrm{n}} \leq 0.2 \mathrm{f}^{\prime}{ }_{\mathrm{c}}$ or $8 \mathrm{MPa}$ & $\begin{array}{r}\text { Max } \\
\text { Calcul }\end{array}$ & $\begin{array}{l}7.0 \\
: 7 \mathrm{MPa} \\
\text { ted: } 1 \mathrm{MPa}\end{array}$ & \multicolumn{2}{|c|}{$\begin{array}{c}7.0 \\
\text { Max.: } 7 \mathrm{MPa} \\
\text { Calculated: } 1 \mathrm{MPa}\end{array}$} & \multicolumn{2}{|c|}{$\begin{array}{c}5.6 \\
\text { Max.: } 7 \mathrm{MPa} \\
\text { Calculated:1.25 MPa }\end{array}$} \\
\hline Shear reinforcement & $A_{v}=V_{s} \frac{s_{2}}{f_{y t} d}$ & $\begin{array}{l}\text { Req.: } \\
\text { Prov. }\end{array}$ & $\begin{array}{l}.89 \\
20.2 \mathrm{~mm}^{2} \\
78.5 \mathrm{~mm}^{2}\end{array}$ & \multicolumn{2}{|c|}{$\begin{array}{c}\quad 3.89 \\
\text { Req.: } 20.2 \mathrm{~mm}^{2} \\
\text { Prov.: } 78.5 \mathrm{~mm}^{2} \\
\end{array}$} & \multicolumn{2}{|c|}{$\begin{array}{l}\quad 1.49 \\
\text { Req.: } 52.6 \mathrm{~mm}^{2} \\
\text { Prov.: } 78.5 \mathrm{~mm}^{2}\end{array}$} \\
\hline Minimum shear reinforcement & $A_{v}=\frac{0.7 b_{w} s_{2}}{f_{y t}}$ & $\begin{array}{l}\text { Min } \\
\text { Prov. }\end{array}$ & $\begin{array}{l}.27 \\
24 \mathrm{~mm}^{2} \\
78.5 \mathrm{~mm}^{2}\end{array}$ & $\begin{array}{r}3 . \\
\text { Min.: } \\
\text { Prov.: } 7\end{array}$ & $\begin{array}{l}7 \\
4 \mathrm{~mm}^{2} \\
.5 \mathrm{~mm}^{2} \\
\end{array}$ & $\begin{array}{r}1 \\
\text { Min.: } \\
\text { Prov.: } 7\end{array}$ & $\begin{array}{l}.78 \\
44 \mathrm{~mm}^{2} \\
78.5 \mathrm{~mm}^{2}\end{array}$ \\
\hline Maximum spacing of shear reinforcement & $\min \left\{\frac{\mathrm{L}_{\mathrm{w}}}{5}, 3 \mathrm{t}\right.$, or $\left.450 \mathrm{~mm}\right\}$ & $\begin{array}{l}\text { Max } \\
\text { Prov }\end{array}$ & $\begin{array}{l}.67 \\
375 \mathrm{~mm} \\
150 \mathrm{~mm}\end{array}$ & $\begin{array}{l}2 . \\
\text { Max.: } \\
\text { Prov.: }\end{array}$ & $\begin{array}{l}7 \\
00 \mathrm{~mm} \\
50 \mathrm{~mm}\end{array}$ & $\begin{array}{l}2 \\
\text { Max.: } \\
\text { Prov.: }\end{array}$ & $\begin{array}{l}.13 \\
320 \mathrm{~mm} \\
150 \mathrm{~mm}\end{array}$ \\
\hline
\end{tabular}

*1 This ratio is calculated for the prototype wall as it is not controlled by other parameters.

*2 This ratio is same for the prototype walls and the corresponding specimens as it depends on the other geometry parameters.

Req.: Required by the code; Prov.: Provided in the specimen; Max: Maximum value allowed by the code; Min.: Minimum value allowed by the code 


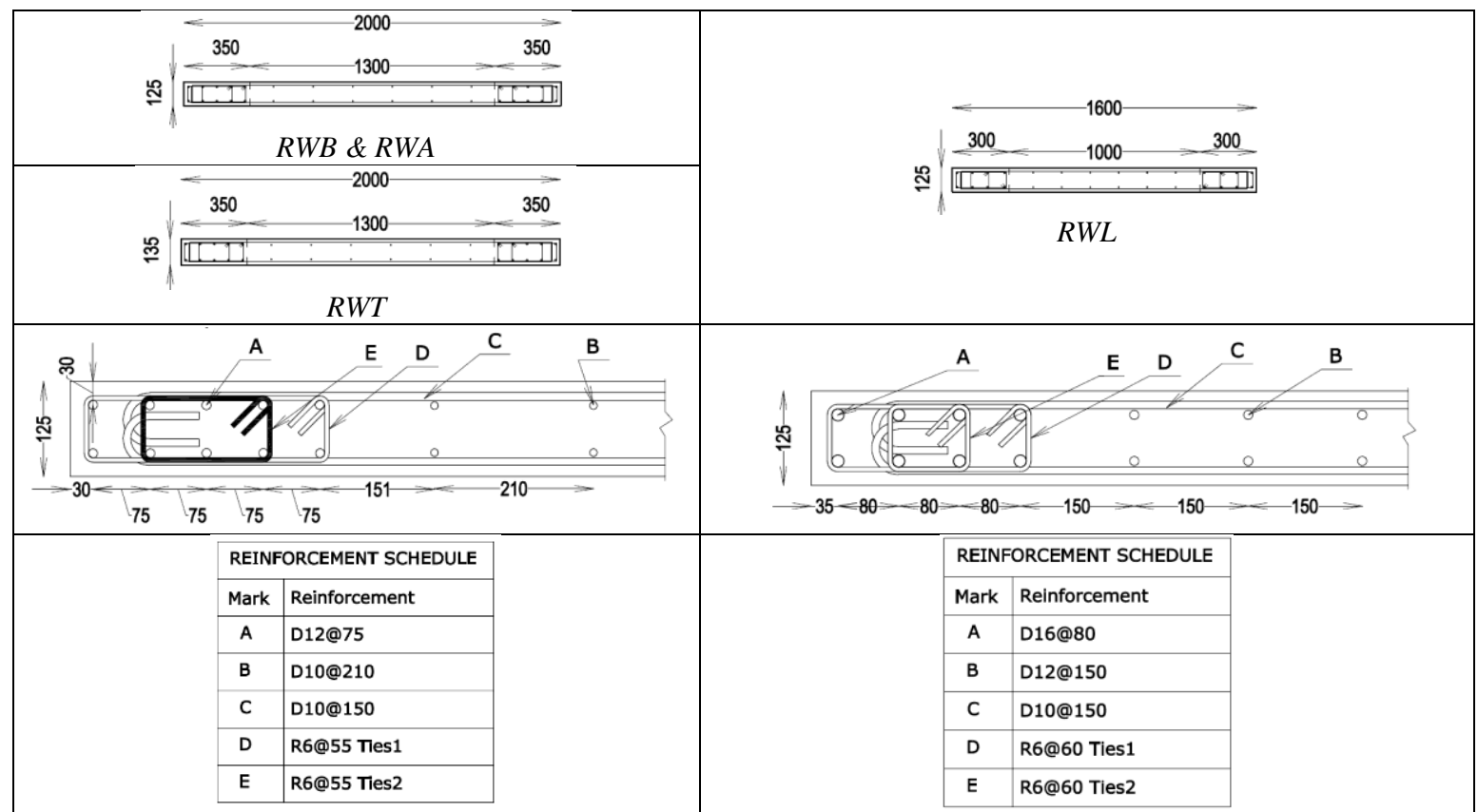

Figure 1. Geometry and reinforcement configuration of the four specimens (D refers to deformed bars, $R$ to plain round bars.

\section{EXPERIMENTAL TEST SETUP}

The test setup was designed to apply the lateral load as well as the bending moment coming from the upper stories. Figure $2 \mathrm{a}$ displays the configuration of horizontal and vertical actuators producing this loading pattern. As the movements of the horizontal and vertical actuators were interdependent, a control program was designed to balance the actuators at each step through an iterative approach so that they comply with the above mentioned loading conditions and satisfy the shearspan of $6.0 \mathrm{~m}$. A safety frame was designed to avoid any instability issues of the loading frame in the event of a sudden wall failure. The specimen was connected to the loading beam by two steel angles bolted to the wall panel through embedded threaded rods and to the loading beam by high strength bolts.

Figure 2a shows the elevation of Specimen RWB where the wall is connected to the loading beam using steel angles clamping the specimen at both sides. This height is the story height determined in the design phase of the specimen. The loading beam was restrained against out-of-plane displacement using roller supports, as shown in Figure $2 \mathrm{~b}$.
These roller supports were positioned at different elevations of the loading beam to restrain the rotation of the loading beam and consequently of the top of the specimen, representing the restraints at the storey level of a structural wall connected to the floor system in a building. A load cell was attached to each roller to measure the variations of the out-of-plane load at different stages of loading (Figure 2b).

The specimens were subjected to an in-plane quasi-static cyclic loading regime with three cycles at each drift level. Figure 3 displays the displacement history of the control point, located at elevation of $2.0 \mathrm{~m}$ from the wall base (Figure 2a), which was used to control the horizontal actuator. As the interstorey drift (not the overall building/wall drift) is considered as a performance limit/target by the New Zealand standard for structural design actions [18], the horizontal displacement within the bottom storey was used to control the loading program. The loading applied by the vertical actuators consisted of the axial load and the bending moment corresponding to every increment of the lateral displacement.

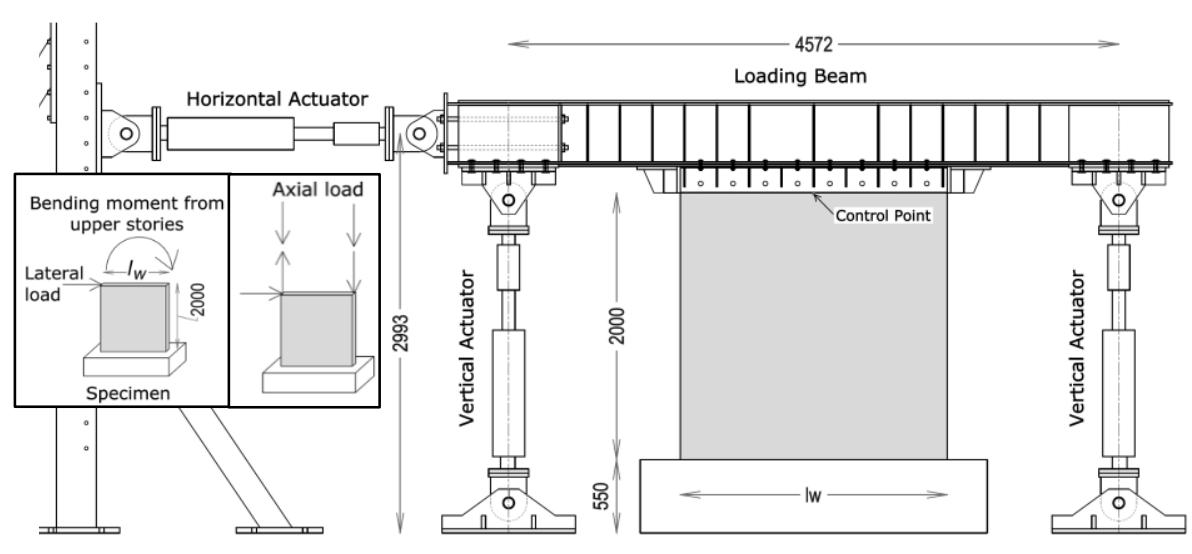

(a)
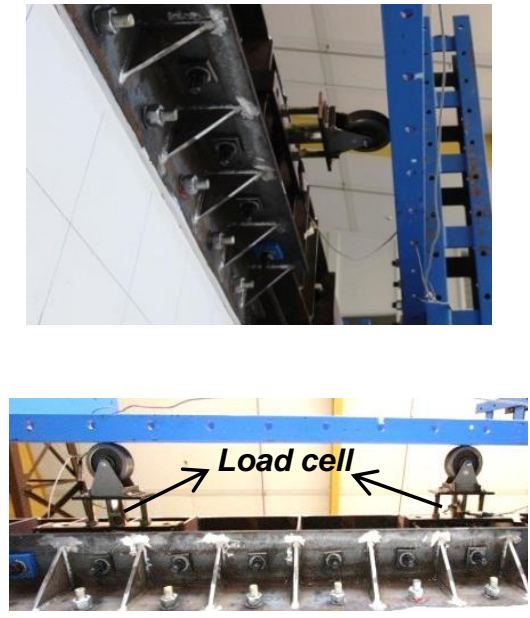

(b)

Figure 2. Test set up: (a) configuration of actuators (units in [mm]); (b) out-of-plane support and connection details of the loading beam. 


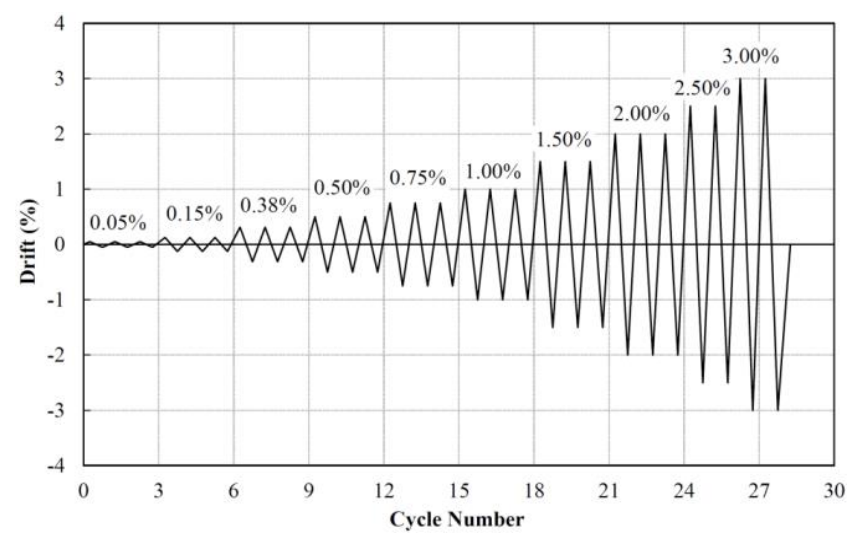

Figure 3. Applied displacement history.

\section{INSTRUMENTATION}

Thirty-six linear potentiometers were attached to the boundary zones at two faces of the wall to measure the vertical displacements of the wall boundary regions at different positions along the wall height. This information could be used to capture the variation of vertical displacements along the wall thickness and identify the loading stage corresponding to the initiation of out-of-plane displacements. Figure $4 \mathrm{a}$ and Figure $4 \mathrm{~b}$ indicate these linear potentiometers in the north and south faces of the specimen, respectively. As it can be seen in Figure $4 \mathrm{~b}$, in addition to the potentiometers attached to the boundary regions, three potentiometers were used along the wall panel and at the base to capture the variation of vertical displacements along $300 \mathrm{~mm}$ distance from the base. This information would help to analytically derive the nonlinear strain profile along the wall length and identify the neutral axis position at different stages of loading. Shear deformation of the wall panel was measured using diagonal potentiometers. Reinforcement strain at different stages of loading, unloading and reloading has been identified as one of the main parameters controlling out-of-plane deformations of rectangular walls $[11,19,20]$. In order to investigate the effect of this parameter, in addition to seventy strain gauges attached to the reinforcement along the halfheight of the wall, couplers were welded to the longitudinal reinforcement at each extreme end to capture the average reinforcement strain along the distance between two couplers $(400-550 \mathrm{~mm})$. Figure $4 \mathrm{c}$ displays a typical string potentiometer used for measuring the out-of-plane deformations of the specimens and their positions along the half height of the wall.

\section{RESPONSE OF THE SPECIMENS}

\section{Specimen RWB}

Specimen RWB was the benchmark specimen. Figure 5 displays the crack pattern of this specimen at different stages of loading. Figure 6 shows its lateral load versus top displacement response. The sequence of events resulting in the failure of the specimen is indicated in this figure.

Initial cracking occurred in this specimen at $0.05 \%$ drift level. As it can be seen in Figure 5, the cracks at this stage were all horizontal flexural cracks mostly located in the boundary zones. At $0.15 \%$ drift level, these horizontal cracks extended more with a diagonal orientation at the central region, and new cracks initiated up to a height of $1750 \mathrm{~mm}$ from the base of the specimen. The maximum crack width at this stage was 0.25 $\mathrm{mm}$ and the cracks were more distributed in the boundary regions but merged into a wider crack in the central panel region.
At $0.38 \%$ drift level, the cracks increased further both in terms of number and length. The previously formed cracks grew slightly wider. The cracks extended up to $1500 \mathrm{~mm}$ out of the whole length of $2000 \mathrm{~mm}$, which shows the considerable movement of the neutral axis position along the wall length. Cracks became wider at $0.5 \%$ drift level, especially the diagonal ones, and the ones developed at the base. At this stage, the specimen reached the yield point. During the $0.75 \%$ drift cycle, the cracks did not increase further in number and the former cracks became wider and extended up to $1750 \mathrm{~mm}$ of the wall length. Large crack opening $(1.3 \mathrm{~mm})$ was observed at the base. During the 3rd cycle of $0.75 \%$ drift, cover spalling started on one face of the wall.

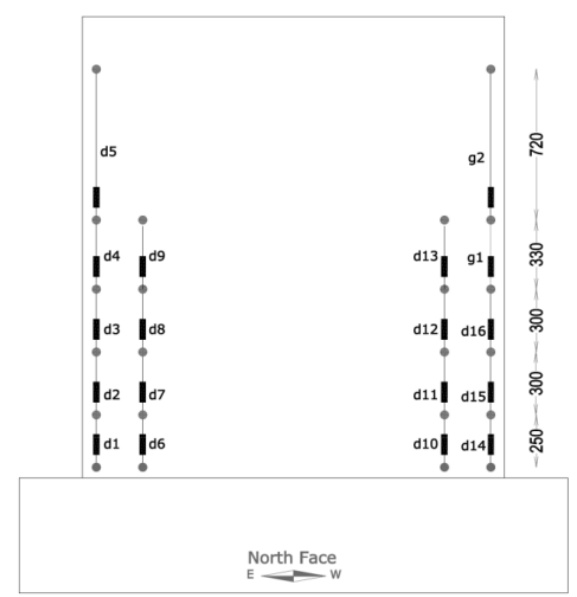

(a)

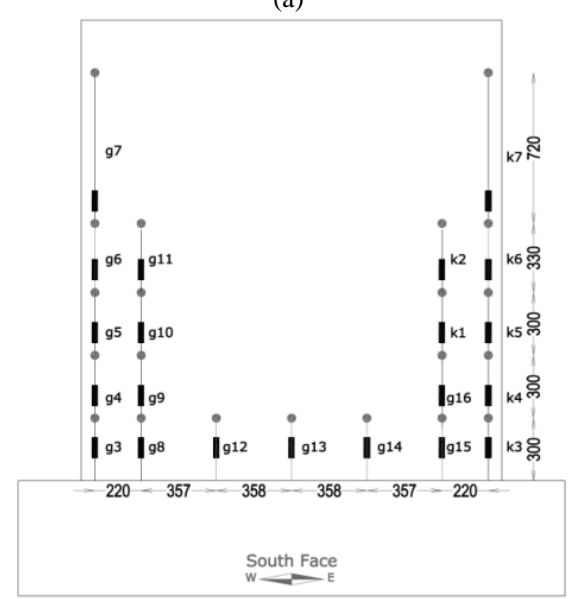

(b)

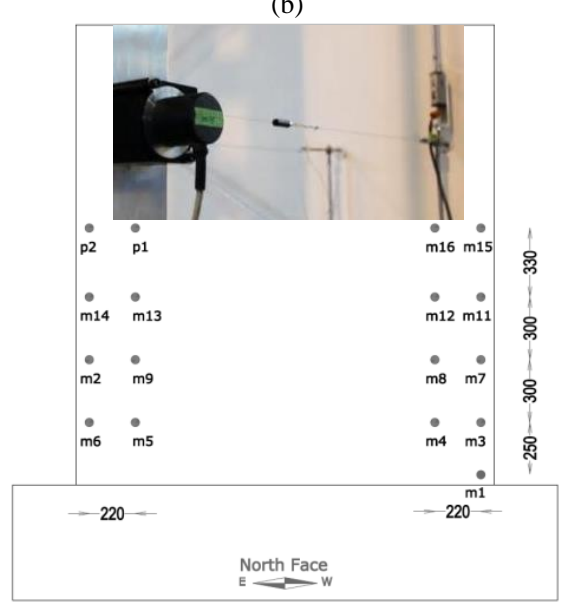

(c)

Figure 4. Instrumentation: (a) potentiometers-north face; (b) potentiometers-south face; (c) strain gauges and welded couplers and potentiometers attached to the couplers for measuring the average reinforcement strain; (d) string potentiometer for measuring out-of-plane displacements. 


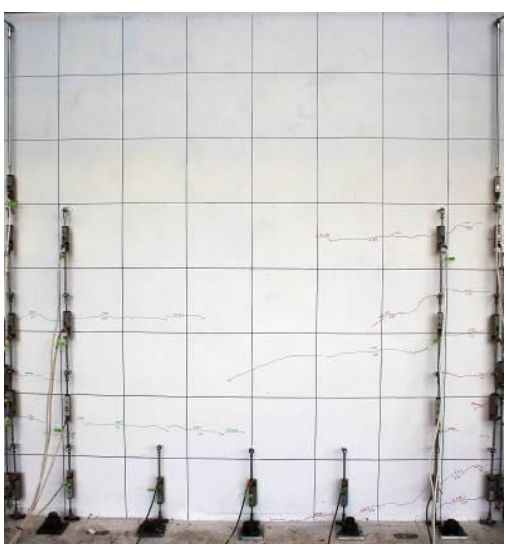

Initial flexural cracks (0.05\% drift)

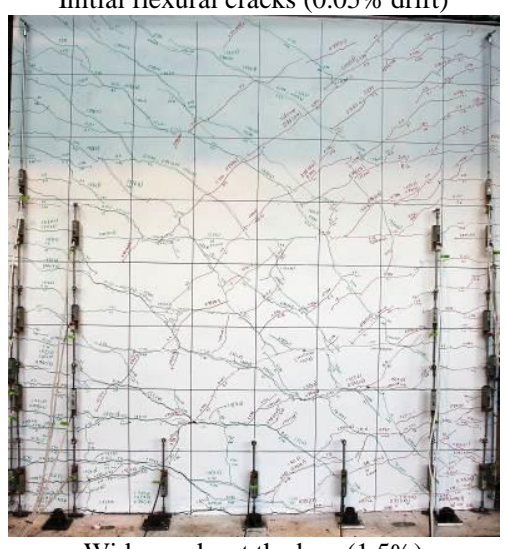

Wide cracks at the base $(1.5 \%)$

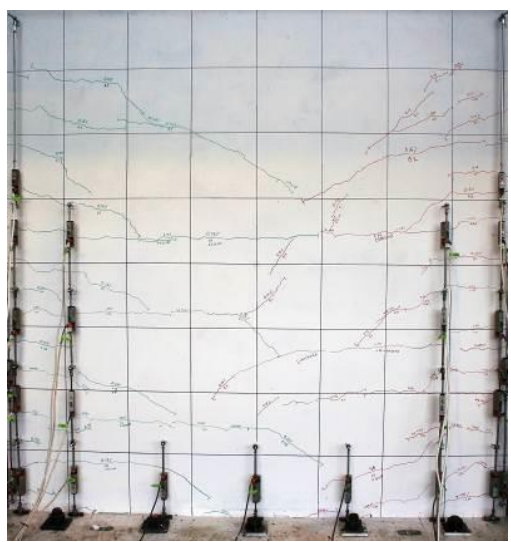

Initial shear cracks $(0.15 \%)$

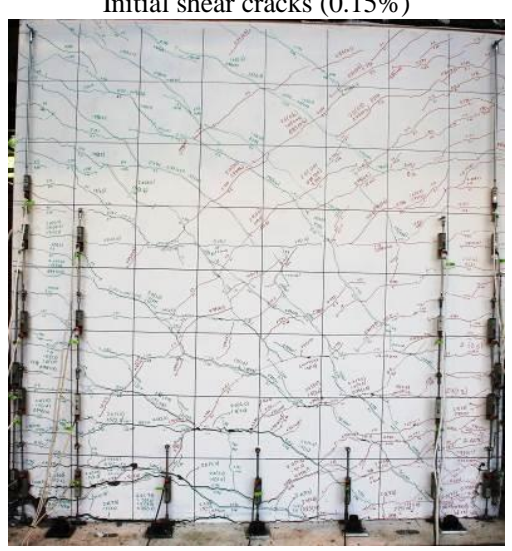

Wider cracks \& bar fracture at the base (2.0\% drift)

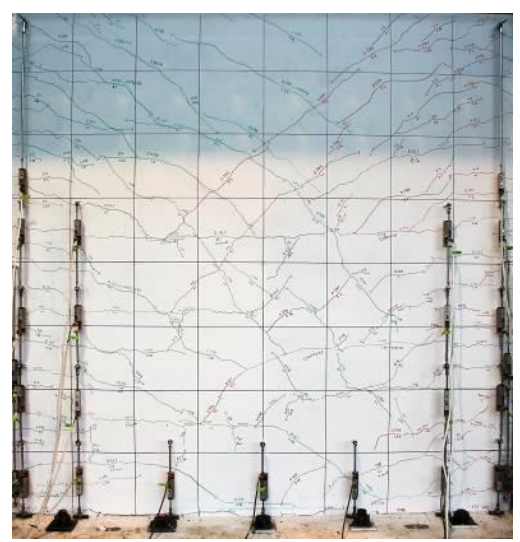

Crack propagation at yield stage $(0.50 \%$ drift $)$

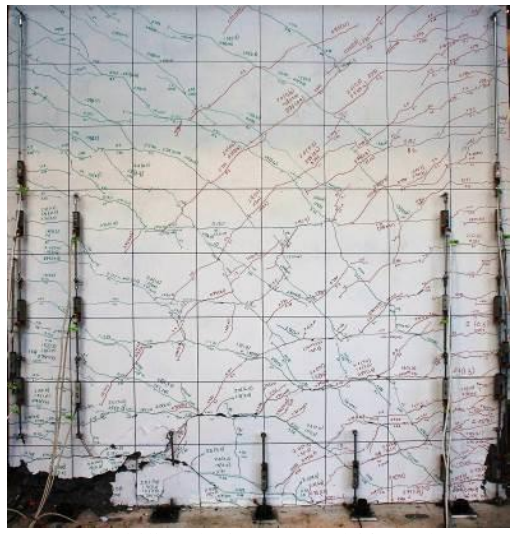

Instability during $2.0 \%$ drift cycle

Figure 5. Crack pattern of Specimen RWB at different stages of loading - grid size 250x250 mm.

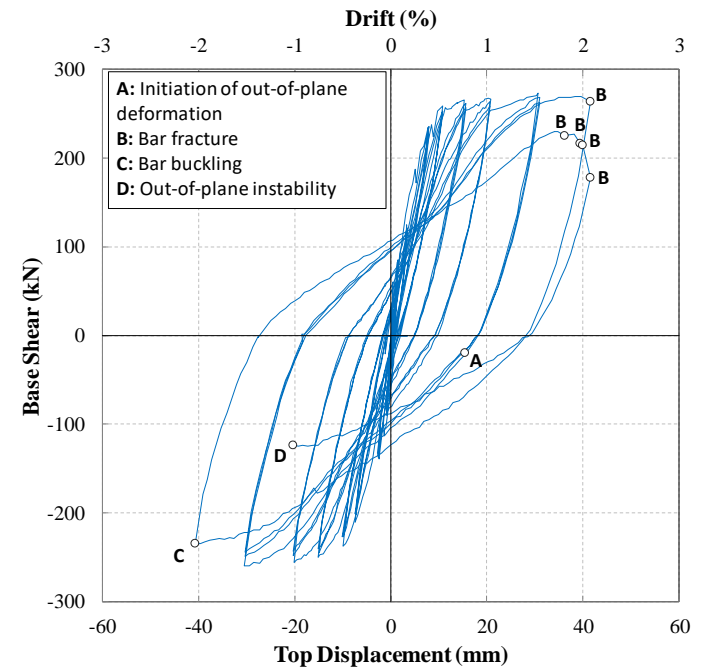

Figure 6. Lateral load vs. top displacement response of Specimen RWB.

The cracks widened further during the $1.0 \%$ and $1.5 \%$ drift cycles. At $1.5 \%$ drift level, the base line crack width was 5.0 $\mathrm{mm}$ along $500 \mathrm{~mm}$ from the extreme tension fibre and gradually decreased to $3.0 \mathrm{~mm}$ and $0.0 \mathrm{~mm}$ at the 1250 and $1750 \mathrm{~mm}$ distance from the tension extreme end, respectively. The cracks within the bottom $375 \mathrm{~mm}$ of the wall height had a similar trend. These cracks were considerably wider when compared to the rest of the wall area. When the specimen was being unloaded and reloaded in the opposite direction, the crack width decreased by about $20-30 \%$ when the load reached zero (static residual crack) and by about $50 \%$ when the wall displacement reached zero. At this stage, as the load carrying capacity of the wall was provided by the reinforcement that had already undergone a large tensile strain, the specimen started to deform in the out-of-plane direction. These wide cracks did not close over the entire wall thickness until about $1.0 \%$ drift level in the opposite direction which is the stage when the out-of-plane deformation of the specimen had recovered. This phenomenon was repeated in both boundary regions at the subsequent cycles of $1.5 \%$ drift level with larger out-of-plane deformations, which was obviously due to increase of the longitudinal reinforcement strain with the number of cycles. The measurements of out-ofplane displacement at different stages of loading are provided in [16].

While reaching the peak displacement of the first $2.0 \%$ drift cycle, a bar in the extreme tension region snapped at the base. The cracks widened within $600 \mathrm{~mm}$ from the base; the base crack width reached $7.0 \mathrm{~mm}$. When the load was applied in the opposite direction, the out-of-plane deformations increased in the west boundary region and reached the maximum value of $17 \mathrm{~mm}$ at about zero displacement. This out-of-plane deformation did not recover completely at the peak displacement of $-2.0 \%$ drift level and the following cycle started with about $6 \mathrm{~mm}$ residual out-of-plane deformation in the west boundary zone. At this stage bar buckling was observed at the base of the compression boundary region (Point C, Figure 6). Point $\mathrm{C}$ was decided based on visual appearance of bar buckling after the cover concrete was spalled. The exact point of initiation of bar buckling could not be detected, and it is likely that the bars might have started to buckle earlier. During the second cycle of $2.0 \%$ drift level, more bar fractures happened at the base of the west boundary region, and the specimen exhibited higher out-of-plane deformations when the load was reversed. Unlike the previous cycle, the out-of-plane deformation did not recover and increased steadily. At this stage, the strength degraded by about 50\% (Figure 6) and the test was interrupted. 


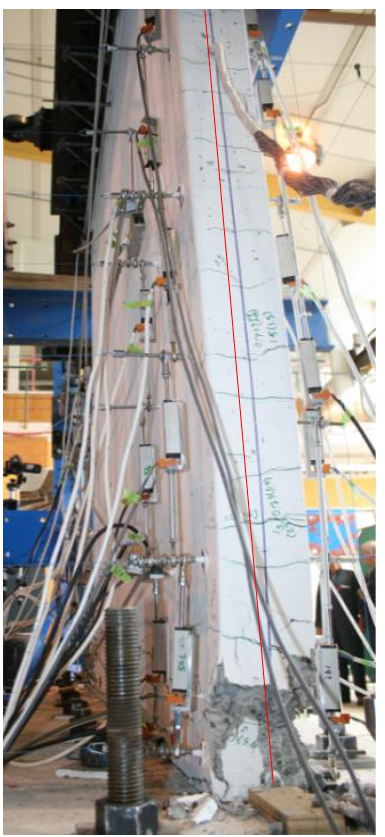

(a)

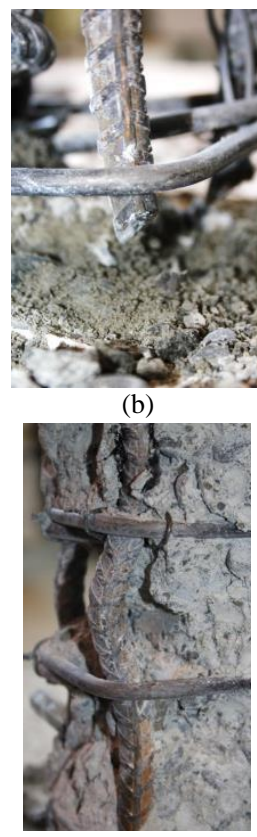

(c)

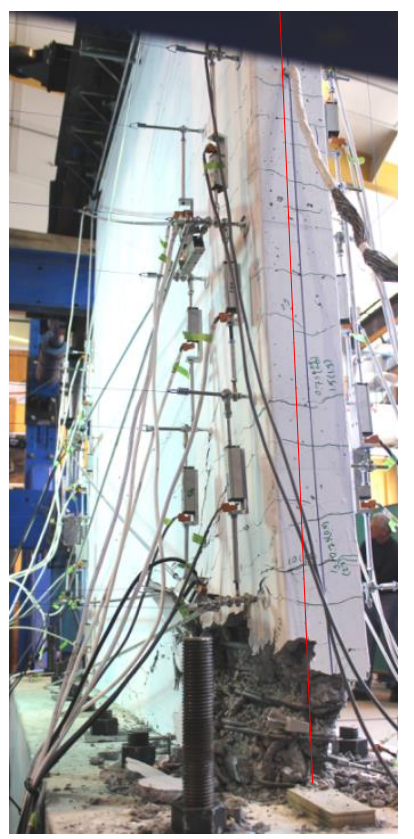

(d)

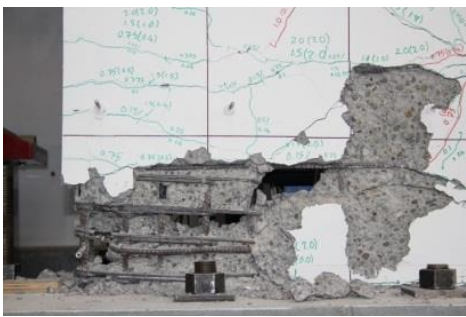

(e)

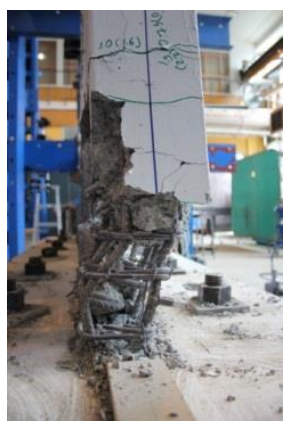

(f)

Figure 7. Response of Specimen RWB: (a) out-of-plane deformation; (b) bar fracture; (c) bar buckling; (d) instability; (e\&f) extent of concrete crushing.

Figure 7 displays some of the observations at ultimate stages of the response of Specimen RWB. As can be seen in this figure, the bar fracture and bar bucking at the base resulted in concrete crushing in this region.

This concrete crushing along with the instability of the reinforcement under compression led to a laterally unstable cross-section, and as the specimen had exhibited out-of-plane deformation at earlier stages, it caused out-of-plane instability of the specimen.

\section{Specimen RWT}

Specimen RWT was the specimen in which the thickness was slightly increased to investigate the effect of thickness on the initiation and development of out-of-plane deformations. Due to the limitations of the test setup, the thickness increase in the scaled specimen was only $10 \mathrm{~mm}(8.0 \%)$, corresponding to an increase of the prototype wall's thickness from $250 \mathrm{~mm}$ to 270 $\mathrm{mm}$. Figure 8 displays the lateral load versus top displacement response of Specimen RWT. The sequence of events resulting in the failure of the specimen is also indicated in this figure. The crack pattern on this specimen was similar to the one observed on the benchmark Specimen RWB. Therefore, the crack patterns for this specimen are not shown again, but the sequence of events leading to the instability of this specimen is summarized in the text below.

The cracking first initiated at $0.05 \%$ drift level up to the height of about $1.0 \mathrm{~m}$ from the base. The cracks extended up to the whole height of the specimen with wide horizontal cracks at the base $(0.3 \mathrm{~mm}$ crack width) as well as some wide diagonal cracks (0.2-0.3 mm crack width). During the $0.5 \%$ drift cycles, the cracks became wider but new cracks did not form in the specimen. Thereafter, increase in crack width was mostly localized at the base. Some more cracks emerged along the height at $0.75 \%$ drift level and the crack width reached 1.5 $\mathrm{mm}$ at the base.

The crack width further increased during the $1.0 \%$ and $1.5 \%$ drift cycles. At $1.5 \%$ drift level, out-of-plane deformations started in the west boundary region during the first cycle when the specimen was unloaded from the peak positive displacement and was being reloaded in the opposite direction. The maximum value of out-of-plane displacement was $3 \mathrm{~mm}$ in this boundary region. A relatively wide crack at the base (with $5.0 \mathrm{~mm}$ crack width), which remained wide open during unloading and even reloading in the opposite direction, was a sign of larger tensile strains at the base of the specimen. Outof-plane deformations initiated in the east boundary zone, as well, during the first cycle of $1.5 \%$ drift level with maximum out-of-plane displacement of $6 \mathrm{~mm}$. At this drift level, cover spalling was observed in both boundary zones. A buckled bar was observed in the east boundary zone during the third cycle of this drift level (Point B, Figure 8).

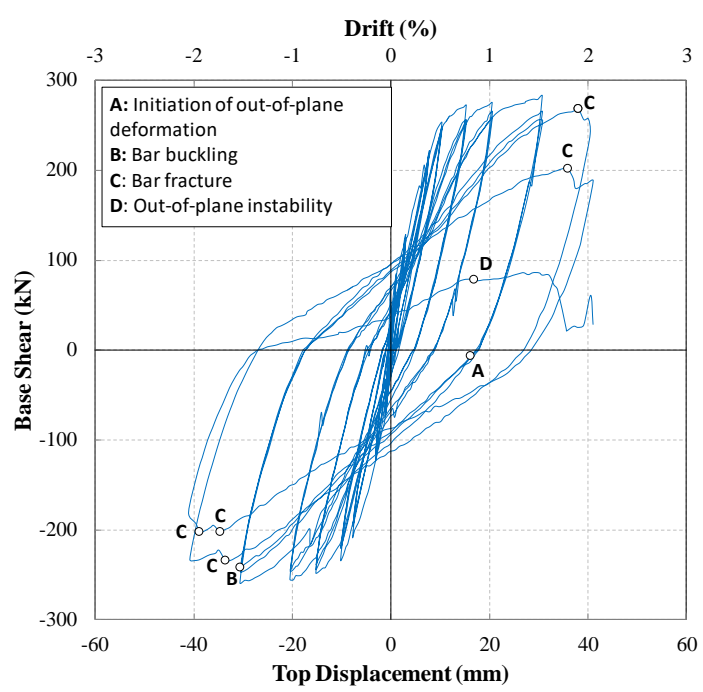

Figure 8. Lateral load vs. top displacement response of Specimen RWT.

While reaching the peak displacement in the 1st cycle of $2.0 \%$ drift level, one bar fractured in the west boundary zone accompanied by a degradation observed in the loaddisplacement curve. The buckled bar in the east boundary straightened during the load reversal at $-1.55 \%$ drift level. One bar also buckled in the west boundary zone, and one bar fractured in the east boundary at $-1.8 \%$ drift, which resulted in another abrupt drop in the load-displacement curve. The fractured bar is the same bar that had buckled in the previous peak. Different instances of bar fracture are denoted as " $\mathrm{C}$ " in Figure 8 , whereas only the initial bar buckling is shown in this 
figure (Point B) as bar fracture was generally accompanied by bar buckling in the opposite boundary zone.

The maximum out-of-plane displacement increased to about $16 \mathrm{~mm}$ at around zero drift level. Two more bars fractured in the west boundary region when the specimen was at $1.85 \%$ drift level. This successive occurrence of bar fracture and bar buckling followed by concrete crushing exacerbated the resistance of the severely cracked wall section against out-ofplane deformations and the specimen became unstable when reloading toward $+2.0 \%$ drift level after unloading from $-2.0 \%$ drift level.
The overall response of Specimen RWT was very similar to the one of Specimen RWB, and its failure initiated with outof-plane deformation and included bar fracture and bar buckling at later stages of loading. However, the values of outof-plane displacement were smaller in Specimen RWT compared to Specimen RWB when bar fracture had not come into effect in both specimens, which could be due to the slight increase in the wall thickness. Figure 9 and Figure 10 display the cracking, cover spalling, bar buckling and bar fracture observed in this test and Figure 11 shows the instability of this specimen.
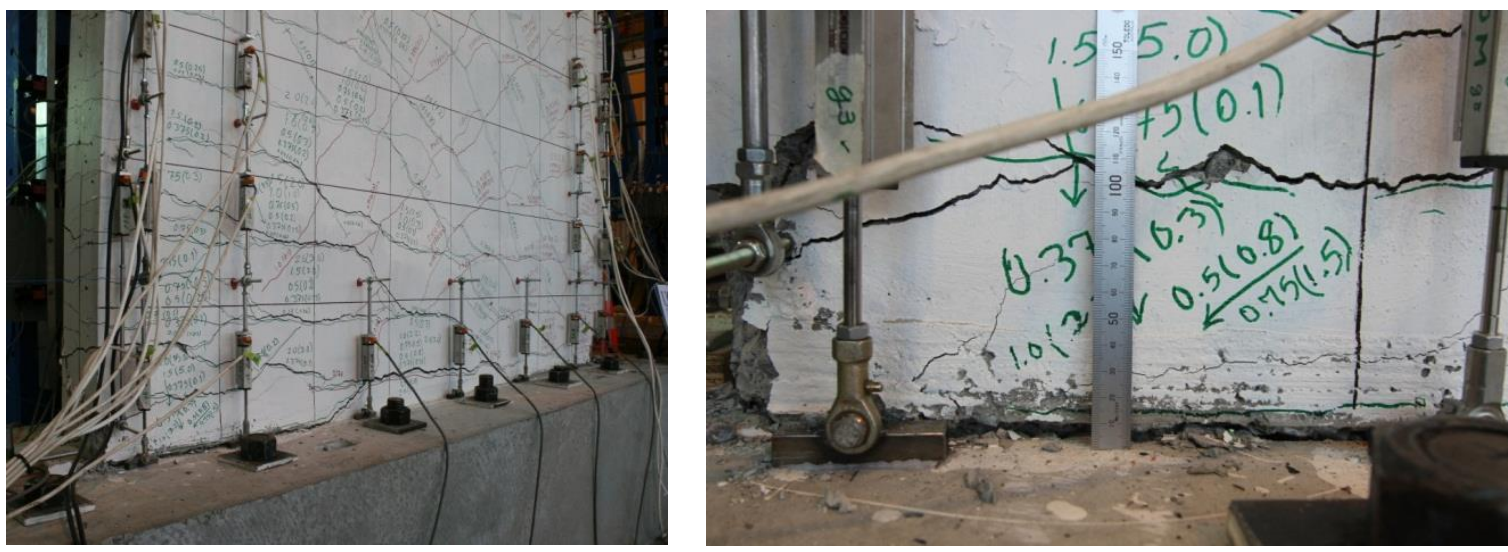

Figure 9. Wide cracks at $+2.0 \%$ drift level-Specimen RWT.

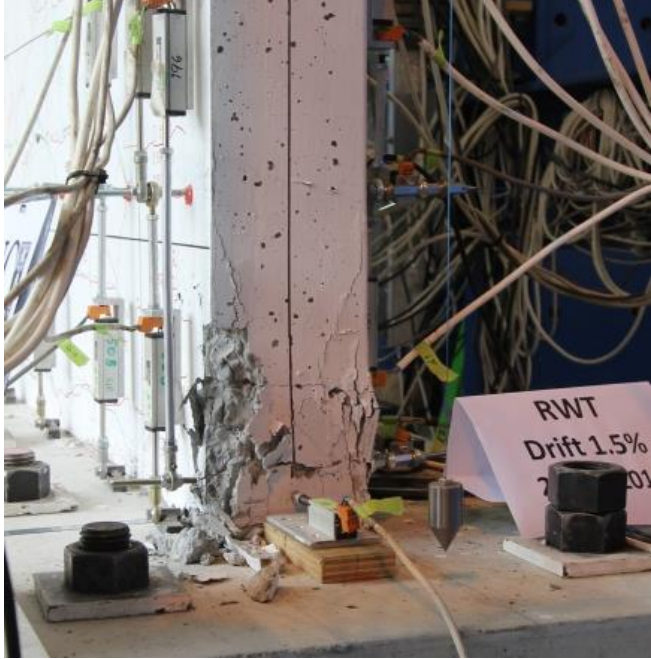

(a)

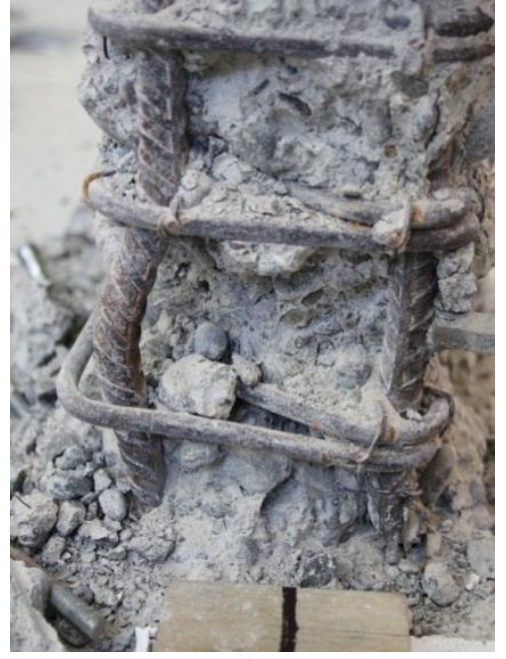

(b)

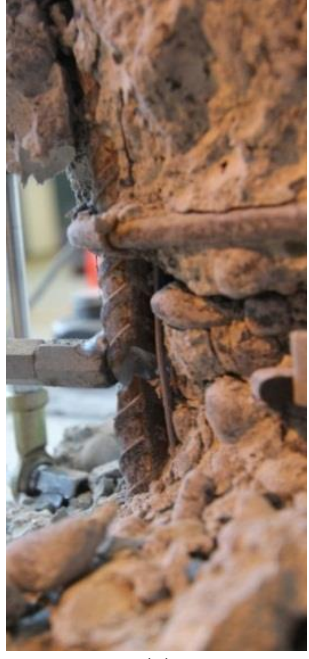

(c)

Figure 10. Development of local damage in Specimen RWT: (a) Cover spalling; (b) bar buckling; (c) bar fracture.
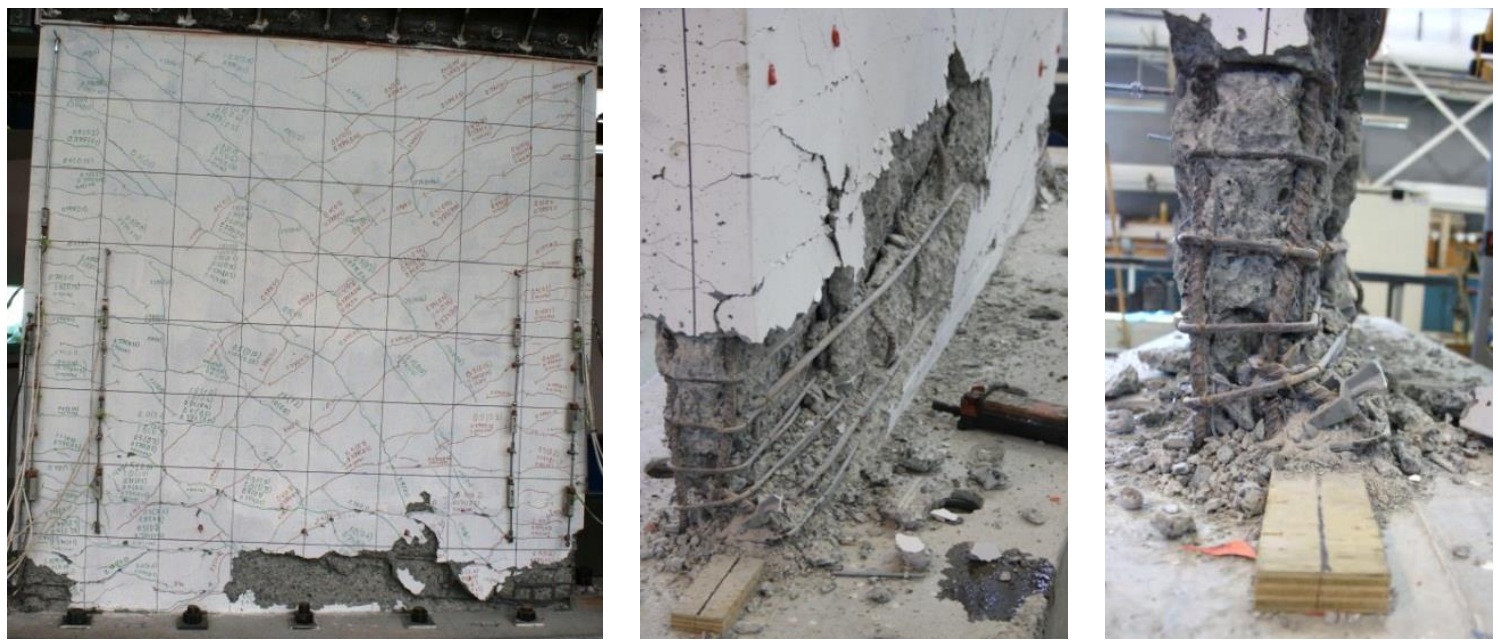

Figure 11. Instability of Specimen RWT. 


\section{Specimen RWL}

Specimen RWL had a $20 \%$ reduction in length when compared to the benchmark RWB to investigate the effect of wall length on initiation and development of out-of-plane deformations. Therefore, this specimen had larger reinforcement ratios in the boundary regions and in the web to provide a flexural capacity close to the other specimens. The over-strength moment capacity of Specimens RWB and RWT was calculated to be $1522 \mathrm{kNm}$ and that of Specimen RWL was $1485 \mathrm{kNm}$. Figure 12 displays the lateral load-top displacement response of the specimen. The failure pattern of the specimen was pure out-of-plane instability and neither bar fracture nor bar buckling was observed in the test. The out-ofplane deformation initiated at Point A when the specimen was unloaded from $1.5 \%$ drift and was starting to reload in the opposite direction. The out-of-plane deformation recovered completely as the specimen was reloaded in the opposite direction. This out-of-plane displacement recovery happened at early stages of loading. During $2.5 \%$ drift cycles, the out-ofplane deformation did not recover completely, and the specimen started to exhibit residual out-of-plane displacement. The residual out-of-plane displacement increased with the number of cycles and the specimen became unstable at Point $\mathrm{B}$ where the abrupt strength degradation was observed.

Figure 13 displays the crack pattern of the specimen at different stages of loading. The grid size was $200 \times 200 \mathrm{~mm}$ for this specimen. The specimen did not exhibit any cracking at $0.05 \%$ drift cycle. The first cracking happened at $0.06 \%$ drift during the $0.15 \%$ drift cycle at about $550 \mathrm{~mm}$ from the base. As it can be seen in Figure 13, the flexural cracks were distributed along the whole height of the specimen during the $0.15 \%$ drift cycle. The crack width was almost equal throughout the wall at this stage and was about $0.04 \mathrm{~mm}$. The number of horizontal cracks increased significantly at $0.38 \%$ drift level. These cracks were observed mostly along the boundary regions. A considerable number of diagonal cracks were observed throughout the panel at this drift level, as well. The distribution of crack width was almost uniform all over the specimen which can be attributed to the fact that the specimen represented the plastic hinge region of a four-storey wall. The cracks became wider and increased in number at $0.5 \%$ drift level. During the first cycle of $0.75 \%$ drift, a wide crack $(1 \mathrm{~mm})$ developed at the base and extended up to 1150 $\mathrm{mm}$ along the wall length (70\% of the wall length). Another wide crack was observed at about $200 \mathrm{~mm}$ from the base in the boundary region which did not extend more than $600 \mathrm{~mm}$ along the wall length. According to the lateral load-top displacement response of the specimen, this is the stage where overall yielding of the specimen happened. During the $1.0 \%$ drift cycles, the width of horizontal cracks in the boundary region increased considerably within $600 \mathrm{~mm}$ from the base and the width of diagonal central region cracks increased within $1000 \mathrm{~mm}$ from the base. Cover spalling was observed at the extreme compression end of the specimen during the $1^{\text {st }}$ cycle of $1.0 \%$ drift.

At the peak of the $1.5 \%$ drift cycle, new horizontal cracks had formed in the boundary regions between former cracks which merged into wide diagonal cracks in the central region. This can be attributed to the different bar sizes in the boundary and central regions. At this stage, wide boundary cracks were uniformly distributed within $700 \mathrm{~mm}$ from the base and had an average crack width of $1.3 \mathrm{~mm}$. These cracks merged in the panel region and resulted in diagonal cracks that had an average crack width of $1.7 \mathrm{~mm}$. Unlike the benchmark specimen, the crack width was uniformly high within $35 \%$ of the wall height from the base and was not significant at the base only. The initial out-of-plane displacement $(1 \mathrm{~mm})$ happened during the $1^{\text {st }}$ cycle of $1.5 \%$ drift in the west boundary, and it increased in the subsequent cycles.
Quite a number of small cracks occurred during the $2.0 \%$ drift cycle, merging together and forming wide cracks in the panel region. The wide cracks had extended up to $50 \%$ of the wall height at this stage. Unlike Specimens RWB and RWT, no bar fracture or bar buckling happened during $2.0 \%$ drift cycles, and the out-of-plane displacement increased to about $7 \mathrm{~mm}$ and $10 \mathrm{~mm}$ in the $1^{\text {st }}$ and $3^{\text {rd }}$ cycles of $2.0 \%$ drift level, respectively.

The crack pattern at $2.5 \%$ drift level was similar to the one at $2.0 \%$ drift level, and the crack width had increased, particularly the diagonal cracks. The wide cracks in the tension boundary region extended up to $1350 \mathrm{~mm}$ from the base with a uniform distribution of crack width. When the load was reversed from the peak of $2.5 \%$ drift cycle, the cracks in the tension region were wide open, and were still wide when the specimen was being reloaded in the opposite direction. Being spaced at an average distance of $120 \mathrm{~mm}$, these residual cracks had an average crack width of $0.7 \mathrm{~mm}$. At this stage, the out-of-plane deformation increased significantly in the compression boundary region and was clearly visible. The outof-plane deformation did not recover completely at this stage since the compressive stresses increased in the inner face of the out-of-plane displacement profile (where the crack closure initiated) along with reloading in the opposite direction and resulted in concrete crushing in one face of the wall. The outof-plane deformation increased in the right boundary element as well when the specimen was being unloaded and reloaded towards the positive peak of the $3.0 \%$ drift cycle. Following the same trend as the previous cycles, the out-of-plane deformation increased up to the state where the cracks started closing in one face of the wall resulting in an increase of compressive stresses in this face and recovery of the out-ofplane deformation. During unloading from $+3.0 \%$ drift level and reloading towards $-3.0 \%$ drift level, the out-of-plane deformation increased in the left boundary region. However, as the cracks generated in this boundary region during the $+3.0 \%$ drift were wider than the previous cycle at $2.5 \%$ drift level, the crack did not close and the out-of-plane deformation increased considerably leading to out-of-plane instability of the wall. Figure 14 shows out-of-plane instability failure of this specimen. The measurements of out-of-plane displacement at different stages of loading are provided in [16].

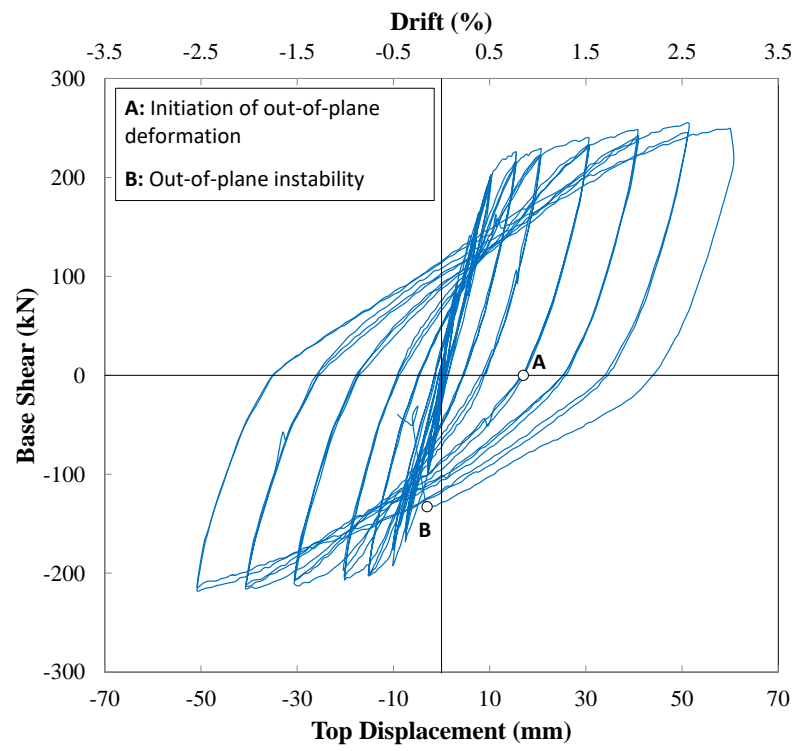

Figure 12. Lateral load vs. top displacement response of Specimen RWL. 


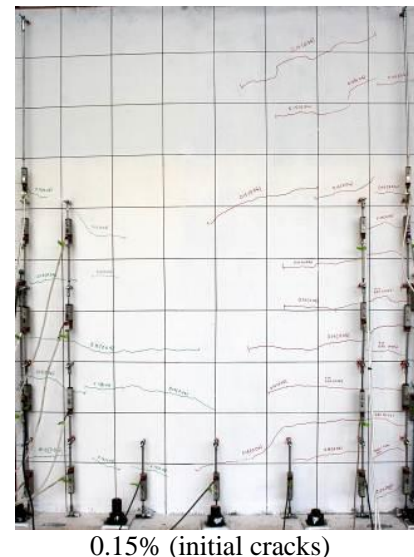

$0.15 \%$ (initial cracks)

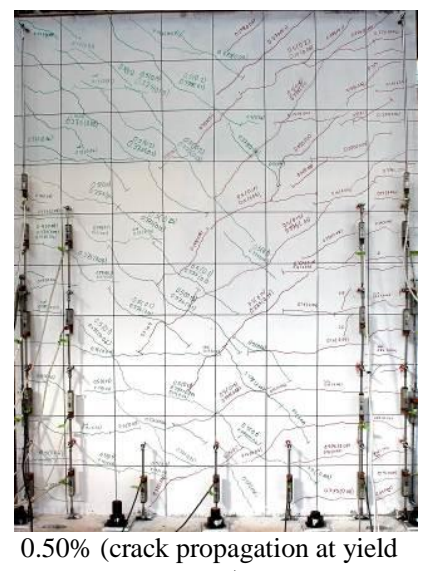

stage)

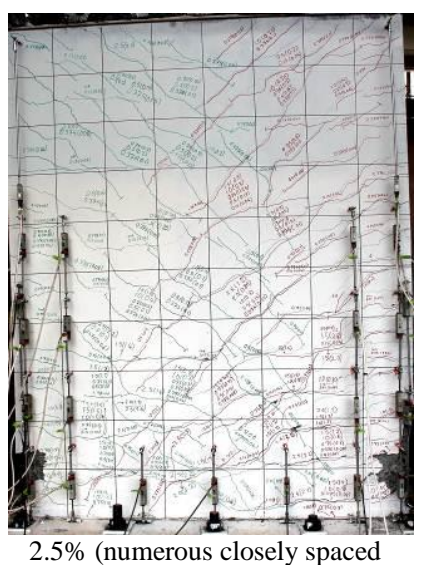

cracks)

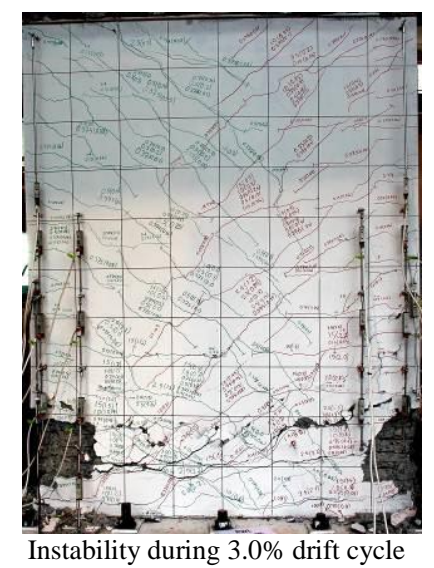

Figure 13. Crack pattern of Specimen RWL at different drift levels - grid size $200 \times 200 \mathrm{~mm}$.
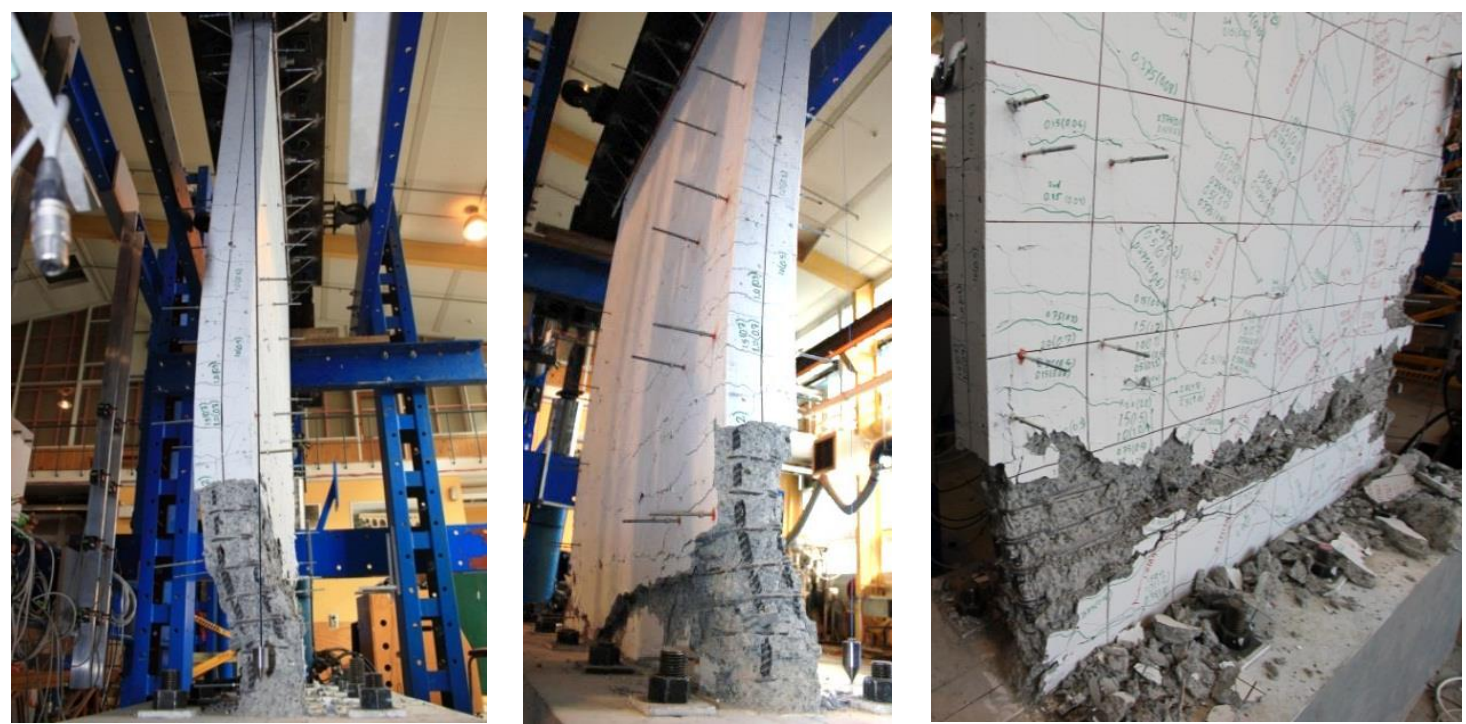

Figure 14. Out-of-plane instability of Specimen RWL.

In literature [21, 22], asymmetric spalling of concrete cover has been postulated to be one of the factors contributing to out-of-plane deformation of rectangular walls under cyclic loading. In this section, the effect of cover spalling on development of out-of-plane deformation is investigated. Figure 15 shows the initiation and development of cover spalling observed in the east boundary region of Specimen RWL. As can be seen in this figure, although $1.5 \%$ and $2.0 \%$ drift levels correspond to initiation and increase of out-ofplane deformations, the cover concrete had spalled off quite symmetrically at these stages. Also, considering the very limited area of spalled cover concrete compared to the length of boundary regions, its asymmetric spalling would not have a noticeable effect on initiation and development of out-of-plane deformation. Furthermore, the onset of out-of-plane deformation is generally associated with unloading from a peak displacement level. At this stage, the cracks are wide open and the response of the section is mainly dependent on the reinforcement. Therefore, any asymmetric response of concrete would not be influential on the evolution of out-ofplane deformation. However, the excessive amount of out-ofplane deformation can result in formation of asymmetric cover spalling, which will understandably occur at the elevation with maximum out-of-plane deformation.

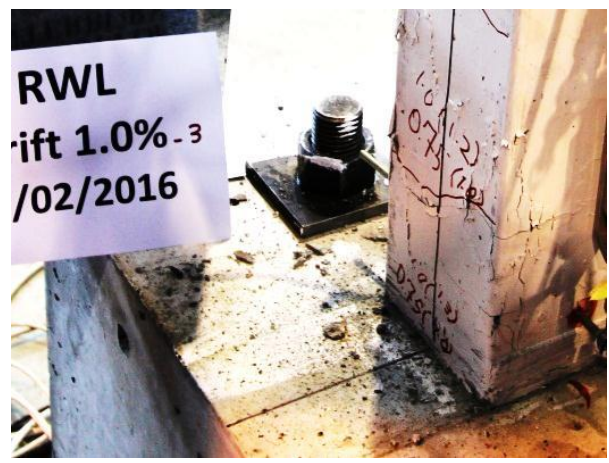

(a)

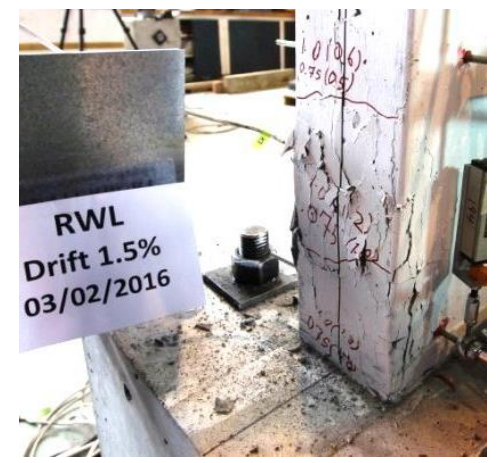

(b)

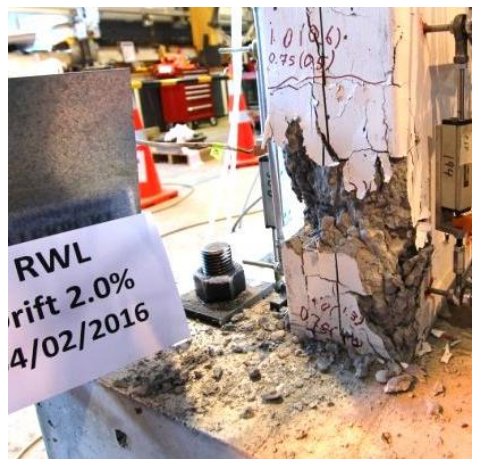

(c)

Figure 15. Development of cover spalling for Specimen RWL: (a) $1.0 \%$ drift; (b) $1.5 \%$ drift; (c) $2.0 \%$ drift. 


\section{KEY STAGES OF WALL RESPONSE AND OBSERVED FAILURE MODES}

All three specimens exhibited flexural cracks along the boundary regions and within about half of the wall height at initial stages of the loading. On further loading, these cracks developed along the whole height of the storey level and diagonal cracks appeared in the panel region of the specimens. The number of cracks increased in Specimens RWB and RWT up to the overall yielding of the specimen, after which the width of the existing cracks increased. As for Specimen RWL, the number of cracks continued increasing along with the gradual increase of crack width throughout the loading of the specimen. Average values of crack width and the number of cracks within $300 \mathrm{~mm}$ elevation from the base of Specimens RWB, RWT and RWL corresponding to different drift levels are given in Table 6 . As can be seen in this table, the crack width of all the specimens increased considerably after overall yielding $(0.5 \%$ drift). The ratio of this increase was significantly higher in Specimens RWB and RWT while the crack width of Specimen RWL increased rather linearly. After $0.75 \%$ drift, the number of cracks within $300 \mathrm{~mm}$ spacing from the base did not increase in Specimens RWB and RWT, while the number of cracks increased steadily in Specimen RWL. Figure 16 displays the average tensile strain measurements along the east boundary regions of Specimens RWB and RWL corresponding to $1.0 \%, 1.5 \%$ and $2.0 \%$ drift levels. Specimen RWT exhibited a similar strain distribution as Specimen RWB and hence is not included in this figure.

As the tensile strain distribution of the boundary region reinforcement reached a critical value along a sufficient height of the wall, all three specimens exhibited out-of-plane deformations during the $1.5 \%$ drift cycles. During unloading and reloading in this cycle, the maximum out-of-plane deformation was measured at about $600 \mathrm{~mm}$ (30\% of the wall height) from the wall base. This out-of-plane deformation is in line with numerical model predictions and is believed to evolve as a result of large tensile strains developed in the boundary region longitudinal reinforcement which prevent crack closure under compressive forces during loading in the opposite direction. The extent of this out-of-plane deformation was different in different specimens due to the difference in length and thickness.

Further concentration of tensile strains at the wall base in the subsequent cycles $(2.0 \%$ drift) was observed in Specimens RWB and RWT, resulting in a significant increase in crack width within the base region (Table 6 and Figure 16). The excessive amount of tensile strain at the base as well as the effects of cyclic loading caused a premature bar fracture in this region. The bar fractured when the specimen reached the maximum displacement during the first $2.0 \%$ drift cycle. At this stage, the tensile strain at the wall base exceeded 0.06 .

In addition to bar fracture, bar buckling was also observed during the $2.0 \%$ drift cycles in Specimens RWB and RWT although buckling resistance provisions of NZS3101:2006 (Table 5) were satisfied. The bar buckling mode of these specimens, shown in Figure $7 \mathrm{~d}$ and Figure 10b, indicates that the effective buckling length is higher than the transverse reinforcement spacing. Therefore, the assumption of buckling length being limited to the distance between two adjacent hoops or ties is not necessarily true in practice. The lateral anti-buckling stiffness, which depends on the diameter and configuration of the transverse reinforcement, would understandably affect the effective buckling length of the longitudinal reinforcement and should be taken into account. The buckling model proposed by Dhakal and Maekawa [23] accounts for the effect of the axial stiffness of the transverse reinforcement in calculation of the buckling length. The effect of cyclic loading which induces large compressive stresses on the bars with large residual strains until crack closure should not be neglected.

The bar fracture and bar buckling would rapidly transfer the compressive stresses to concrete resulting in fast development of concrete crushing at the base, which in turn leads to a laterally unstable cross section. Therefore, the considerable change in strain distribution along the height of the wall, triggering bar fracture and bar buckling at the wall base (during $2.0 \%$ drift cycles), is believed to have interfered with progression of the out-of-plane deformation that had initiated during the previous drift cycle $(1.5 \%$ drift cycle) and have generated a localized out-of-plane instability. This local instability is different from the global instability of the specimen that could have occurred if the progression of outof-plane deformation was not interrupted by other failure patterns. This type of out-of-plane instability can be classified as a secondary failure mode [24], triggered by concrete crushing in the compression boundary zone, with the maximum out-of-plane deformation observed within a limited height from the wall base where the initial failure modes (e.g. bar fracture, bar buckling and concrete crushing) had occurred.

Unlike Specimens RWB and RWT, the tensile strain increased uniformly along the height of boundary region in Specimen RWL and resulted in closely spaced cracks with almost identical crack width. This phenomenon can be attributed to better bond properties provided by larger bar diameters in this specimen. Also, as the length of Specimen RWL was smaller than the other two specimens, the maximum tensile strain developed in the reinforcement was smaller for the same drift level. Therefore, strain localization and consequently bar fracture and bar buckling was not observed in the base region. As a consequence, the out-of-plane deformation, which had initiated during $1.5 \%$ drift cycle, progressed steadily in this specimen and was not obstructed by other failure modes. As the maximum out-of-plane deformation exceeded a stability criterion, the specimen failed in the out-of-plane instability mode during the $3.0 \%$ drift cycle. This out-of-plane instability is different from the local instability observed in Specimens RWB and RWT and is purely originated from the excessive tensile strains developed over a specific height of the wall. Upon loading in the opposite direction, these large tensile strains would result in development of compression yielding in the reinforcement before crack closure can activate contribution of concrete to the load carrying capacity of the wall section. This can trigger out-of-plane instability over a considerable height of the wall from the base.

Table 6. Average crack width and number of cracks in the boundary regions within $300 \mathrm{~mm}$ from the base at different drift levels.

\begin{tabular}{|c|c|c|c|c|c|c|c|c|c|c|c|c|c|c|c|c|c|c|c|c|}
\hline \multirow{2}{*}{ Specimen } & \multicolumn{2}{|c|}{$0.05 \%$} & \multicolumn{2}{|c|}{$0.15 \%$} & \multicolumn{2}{|c|}{$0.38 \%$} & \multicolumn{2}{|c|}{$0.5 \%$} & \multicolumn{2}{|c|}{$0.75 \%$} & \multicolumn{2}{|c|}{$1.0 \%$} & \multicolumn{2}{|c|}{$1.5 \%$} & \multicolumn{2}{|c|}{$2.0 \%$} & \multicolumn{2}{|c|}{$2.5 \%$} & \multicolumn{2}{|c|}{$3.0 \%$} \\
\hline & $\mathrm{CW}$ & NoC & $\mathrm{CW}$ & NoC & $\mathrm{CW}$ & $\mathrm{NoC}$ & $\mathrm{CW}$ & $\mathrm{NoC}$ & $\mathrm{CW}$ & $\mathrm{NoC}$ & $\mathrm{CW}$ & $\mathrm{NoC}$ & $\mathrm{CW}$ & NoC & $\mathrm{CW}$ & NoC & $\mathrm{CW}$ & $\mathrm{NoC}$ & CW & $\mathrm{NoC}$ \\
\hline $\begin{array}{c}\text { RWB \& } \\
\text { RWT }\end{array}$ & 0.06 & 1 & 0.06 & 2 & 0.06 & 3 & 0.15 & 3 & 0.65 & 4 & 2.0 & 4 & 3.5 & 4 & 5.0 & 4 & - & - & - & - \\
\hline RWL & - & - & 0.04 & 1 & 0.08 & 2 & 0.08 & 3 & 0.6 & 3 & 0.8 & 5 & 1.3 & 6 & 1.5 & 6 & 1.8 & 7 & 2.0 & 7 \\
\hline
\end{tabular}




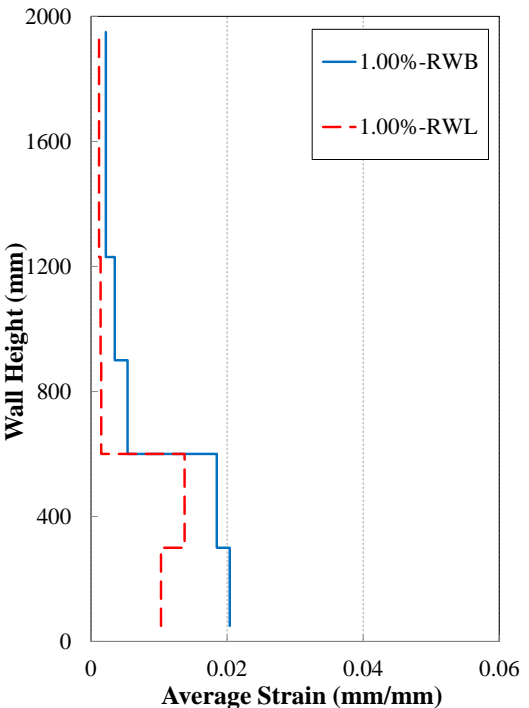

(a)

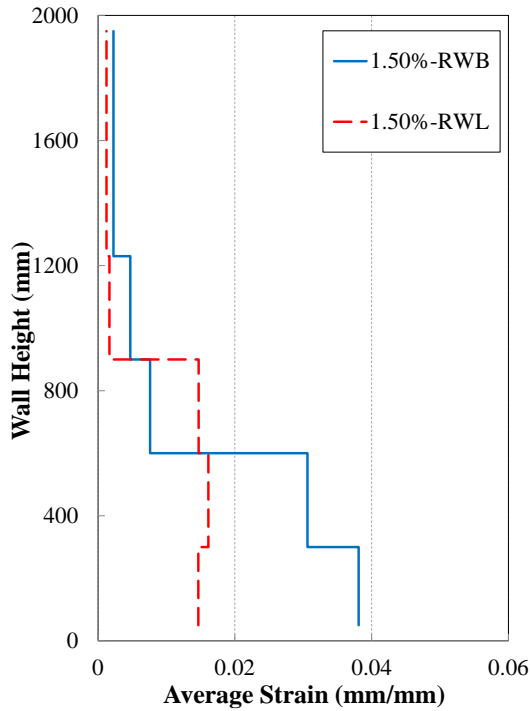

(b)

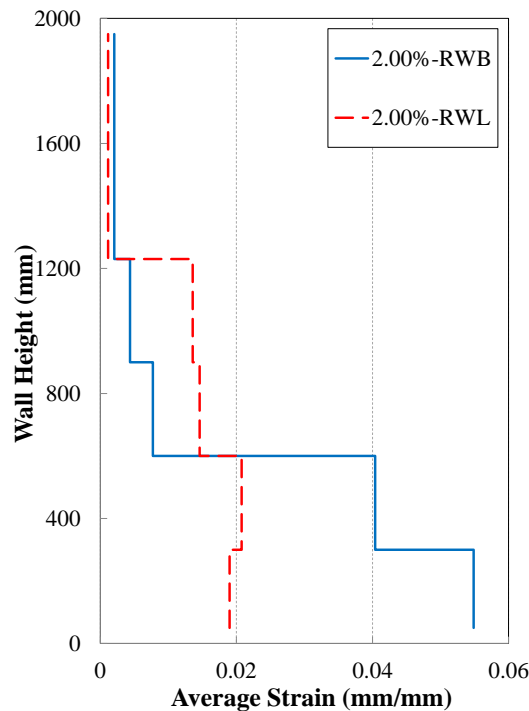

(c)

Figure 16: Average tensile strain profiles along the east boundary region, Specimen RWB vs Specimen RWL.

Table 7: Drift levels corresponding to key stages of wall response.

\begin{tabular}{|c|c|c|c|c|c|c|c|c|c|}
\hline & \multirow[b]{2}{*}{$\begin{array}{l}\text { Crack } \\
\text { initiation }\end{array}$} & \multirow[b]{2}{*}{ Yielding } & \multirow[b]{2}{*}{ Cover spalling } & \multirow[b]{2}{*}{$\begin{array}{c}\text { Initiation of out- } \\
\text { of-plane } \\
\text { deformation }\end{array}$} & \multirow[b]{2}{*}{ Bar fracture } & \multirow[b]{2}{*}{ Bar buckling } & \multirow[b]{2}{*}{$\begin{array}{l}\text { Concrete } \\
\text { crushing }\end{array}$} & \multicolumn{2}{|c|}{ Out-of-plane instability } \\
\hline & & & & & & & & $\begin{array}{c}\text { Global } \\
\text { (main failure) }\end{array}$ & $\begin{array}{c}\text { Local } \\
\text { (secondary } \\
\text { failure) }\end{array}$ \\
\hline RWB & $\begin{array}{c}0.05 \% \\
\left(1^{\text {st }} \text { cycle }\right)\end{array}$ & $\begin{array}{c}0.5 \% \\
\left(1^{\text {st }} \text { cycle }\right)\end{array}$ & $\begin{array}{c}1.0 \% \\
\left(1^{\mathrm{st}} \text { cycle }\right)\end{array}$ & $\begin{array}{c}1.5 \% \\
\left(1^{\mathrm{st}} \text { cycle }\right)\end{array}$ & $\begin{array}{c}2.0 \% \\
\left(1^{\text {st }} \text { and } 2^{\text {nd }}\right. \\
\text { cycles })\end{array}$ & $\begin{array}{c}2.0 \% \\
\left(1^{\text {st }} \text { and } 2^{\text {nd }}\right. \\
\text { cycles })\end{array}$ & $\begin{array}{c}2.0 \% \\
\left(2^{\text {nd }} \text { cycle }\right)\end{array}$ & - & $\begin{array}{c}2.0 \% \\
\left(2^{\text {nd }} \text { cycle }\right)\end{array}$ \\
\hline RWT & $\begin{array}{c}0.05 \% \\
\left(1^{\text {st }} \text { cycle }\right)\end{array}$ & $\begin{array}{c}0.5 \% \\
\left(1^{\text {st }} \text { cycle }\right)\end{array}$ & $\begin{array}{c}1.0 \% \\
\left(1^{\text {st }} \text { cycle }\right)\end{array}$ & $\begin{array}{c}1.5 \% \\
\left(1^{\mathrm{st}} \text { cycle }\right)\end{array}$ & $\begin{array}{c}2.0 \% \\
\left(1^{\text {st }}, 2^{\text {nd }} \text { and } 3^{\text {rd }}\right. \\
\text { cycles })\end{array}$ & $\begin{array}{c}2.0 \% \\
\left(1^{\text {st }}, 2^{\text {nd }} \text { and } 3^{\text {rd }}\right. \\
\text { cycles })\end{array}$ & $\begin{array}{c}2.0 \% \\
\left(3^{\text {rd }} \text { cycle }\right)\end{array}$ & - & $\begin{array}{c}2.0 \% \\
\left(3^{\text {rd }} \text { cycle }\right)\end{array}$ \\
\hline RWL & $\begin{array}{c}0.15 \% \\
\left(1^{\text {st }} \text { cycle }\right)\end{array}$ & $\begin{array}{c}0.5 \% \\
\left(1^{\text {st }} \text { cycle }\right)\end{array}$ & $\begin{array}{c}1.0 \% \\
\left(3^{\text {rd }} \text { cycle }\right)\end{array}$ & $\begin{array}{c}1.5 \% \\
\left(1^{\text {st }} \text { cycle }\right)\end{array}$ & - & - & - & $\begin{array}{c}3.0 \% \\
\left(1^{\text {st }} \text { cycle }\right)\end{array}$ & - \\
\hline
\end{tabular}

Table 7 summarises the sequence of events observed in the tested specimens and the corresponding drift level. Among these milestones of wall response, cracking, yielding, cover spalling and development of out-of-plane deformation did not result in significant changes in the ductile response of the wall. Bar fracture and bar buckling, followed by concrete crushing, led to gradual strength degradation and instability of Specimens RWB and RWT within a limited area at the base (local out-of-plane instability, Table 7). As for Specimen RWL, the progression of out-of-plane deformation, not interrupted by any other failure modes (such as bar fracture and bar buckling), led to instability along a significant height of the wall (more than $70 \%$ of the wall height). This instability, which resulted in abrupt strength degradation of the specimen, is denoted as global out-of-plane instability in Table 7.

\section{CONCLUSIONS}

This paper reported quasi-static cyclic tests on three halfscaled rectangular RC walls designed according to the current New Zealand standard, NZS3101:2006. All three specimens were designed to be flexurally dominated by resisting the brittle shear failure patterns using the capacity design approach and by meeting all design and detailing provisions of the code. The following failure mechanisms were observed in two of the three tested specimens:

- Development of out-of-plane deformation, during 1.5\% drift cycles: Although the minimum thickness requirements of the code were satisfied, a considerable amount of out-of-plane deformation was observed in both specimens (albeit with different values) that could have resulted in out-of-plane instability of the specimens if the following failure modes had not supressed its progression.

- Bar fracture in the boundary regions during $2.0 \%$ drift cycles as the maximum tensile strain at the base exceeded 0.06 in the boundary region: This phenomenon was controlled by the strain localization at the wall base following a considerable bond deterioration along the height of the wall. This issue is not acknowledged by the code as a reason of bar fracture.

- Bar buckling in the boundary regions during $2.0 \%$ drift cycles: The anti-buckling provisions of the code were satisfied, and the bar buckling failure was observed at $2.0 \%$ drift level. The buckling length was not limited to the distance between two adjacent hoops, calling for consideration of the lateral stiffness provided by the transverse reinforcement in buckling resistance calculations of the longitudinal bars.

- Concrete crushing in the boundary regions during $2.0 \%$ drift cycles: Although the confinement requirements of the code were satisfied, development of bar fracture and bar buckling in the boundary zones resulted in excessive compression on concrete and triggered crushing along the whole length of the compression boundary zone and a portion of the panel.

- Local out-of-plane instability at the base following concrete crushing of the boundary region: This type of out-of-plane instability is a secondary failure mode as is triggered by other mechanisms. 
- The third specimen was shorter in length and provided a flexural capacity close to the other two specimens with lower strain demands at the base. Out-of-plane deformation initiated in this specimen at $1.5 \%$ drift and all the other failure patterns mentioned above were suppressed. However, a global type of out-of-plane instability progressed in this specimen and resulted in its abrupt strength degradation during 3.0\% drift cycle. This type of out-of-plane instability has a completely different mechanism compared to the one preceded by other failure modes and is bound to lead to sudden collapse of slender ductile walls which are designed to resist other failure modes. Observation of this mode of failure in some wellconfined walls in the past earthquakes is a case in point

- Cover spalling at the base occurred symmetrically along the wall thickness. Due to the evolution and recovery trend of the out-of-plane deformation (i.e. its maximum value at around $0.0 \%$ drift level, when the compression on concrete cover from in-plane loading is minimum), any asymmetric response of concrete would not affect its initiation. The excessive amount of out-of-plane deformation can however result in formation of asymmetric cover spalling at the elevation with maximum out-of-plane deformation.

- The observed failure patterns of the specimens indicated that the NZS3101:2006 provisions on amount and arrangement/detailing of the transverse reinforcement as well as the minimum thickness requirements are unable to ensure that significant deterioration of flexural performance due to bar buckling, core concrete crushing and out-of-plane deformation are delayed until the intended ductile response is achieved.

\section{ACKNOWLEDGEMENTS}

The authors wish to acknowledge the financial support provided by the Natural Hazard Research Platform (NHRP), the Ministry of Business, Innovation and Employment (MBIE) and the Quake Centre at University of Canterbury to conduct this research as well as the specimen fabrication scrupulously done by Bradford Precast. The considerate technician support provided by Alan Thirlwell at the University of Canterbury is highly appreciated.

\section{REFERENCES}

1 Kam WY, Pampanin S and Elwood K (2011). "Seismic performance of reinforced concrete buildings in the 22 February Christchurch (Lyttelton) earthquake". Bulletin of the New Zealand Society for Earthquake Engineering, 44(4): 239-278.

2 Sritharan S, Beyer K, Henry RS, Chai Y, Kowalsky M and Bull D (2014). "Understanding poor seismic performance of concrete walls and design implications". Earthquake Spectra, 30(1): 307-334.

3 Lu Y, Henry R S, Gultom R and Ma QT (2017). "Cyclic Testing of Reinforced Concrete Walls with Distributed Minimum Vertical Reinforcement". Journal of Structural Engineering, 143(5). DOI:10.1061/(ASCE)ST.1943$541 X .0001723$.

4 Standards New Zealand (2006). "Concrete Structures Standard, NZS 3101:2006 Parts 1\&2”. Standards New Zealand, Wellington.

5 Shegay A, Motter C, Henry RS and Elwood K (2016). "Large scale testing of reinforced concrete walls with high axial loads". New Zealand Concrete Industry Conference, Auckland, New Zealand.

6 Oesterle R (1976). "Earthquake Resistant Structural Walls: Tests of Isolated Walls". Research and Development Construction Technology Laboratories, Portland Cement Association, USA.
7 Paulay T and Goodsir W (1985). "The ductility of structural walls". Bulletin of the New Zealand Society for Earthquake Engineering, 18(3): 250-269.

8 Johnson B (2010). "Anchorage Detailing Effects on Lateral Deformation Components of R/C Shear Walls". Master's Thesis, University of Minnesota, USA.

9 Birely AC (2013). "Seismic Performance of Slender Reinforced Concrete Structural Walls". PhD Thesis, University of Washington, Seattle, USA.

10 Goodsir WJ (1985). "The Design of Coupled Frame-Wall Structures for Seismic Actions". PhD Thesis, University of Canterbury, Christchurch, New Zealand.

11 Chai YH and Elayer DT (1999). "Lateral stability of reinforced concrete columns under axial reversed cyclic tension and compression". ACI Structural Journal, 96(5): 780-789.

12 Creagh A, Acevedo C, Moehle J, Hassan W and Tanyeri AC (2010). "Seismic Performance of Concrete Special Boundary Element". University of Texas Austin and University of California Berkley, USA.

13 Chrysanidis $\mathrm{T}$ and Tegos I (2012). "The influence of tension strain of wall ends to their resistance against lateral instability for low-reinforced concrete walls". Proceedings of the $15^{\text {th }}$ World Conference on Earthquake Engineering (15WCEE), Lisbon, Portugal.

14 Shea M, Wallace JW and Segura C (2013). "Seismic Performance of Thin Reinforced Concrete Shear Wall Boundaries". University of Massachusetts Amherst and University of California Los Angeles, USA.

15 Almeida J, Prodan O, Rosso A and Beyer K (2017). "Tests on Thin Reinforced Concrete Walls Subjected to In-plane and Out-of-plane Cyclic Loading". Earthquake Spectra, 33(1): 323-345.

16 Dashti F (2017). "Out-of-plane Instability of Rectangular Reinforced Concrete Walls Under In-plane Loading”. PhD Thesis, University of Canterbury, Christchurch, NZ.

17 Dashti F, Dhakal RP and Pampanin S (2017). "Numerical Modelling of Rectangular Reinforced Concrete Structural Walls". Journal of Structural Engineering, 143(6): DOI: 10.1061/(ASCE)ST.1943-541X.0001729.

18 Standards New Zealand (2004). "NZS1170.5 Structural Design Actions, Part 5: Earthquake Actions". Standards New Zealand, Wellington.

19 Paulay T and Priestley M (1993). "Stability of ductile structural walls". ACI Structural Journal, 90(4): 385-392.

20 Dashti F, Dhakal RP and Pampanin S (2017). "Validation of a numerical model for prediction of out-of-plane instability in ductile structural walls under concentric inplane cyclic loading". Journal of Structural Engineering, DOI:10.1061/(ASCE)ST.1943-541X.0002013 (In Press).

21 Vallenas JM, Bertero VV and Popov EP (1979). "Hysteretic Behaviour of Reinforced Concrete Structural Walls". Earthquake Engineering Research Centre Report UCB/EERC-79/20, Berkeley, USA.

22 Hilson C, Segura C and Wallace J (2014). "Experimental study of longitudinal reinforcement buckling in reinforced concrete structural wall boundary elements". Tenth US National Conference on Earthquake Engineering (10NCEE), Anchorage, Alaska, USA.

23 Dhakal RP and Maekawa K (2002). "Reinforcement stability and fracture of cover concrete in reinforced concrete members". ASCE Journal of Structural Engineering, 128(10): 1253-1262.

24 Parra P and Moehle J (2014). "Lateral buckling in reinforced concrete walls". Tenth US National Conference on Earthquake Engineering (10NCEE), Alaska, USA. 